\title{
EXPERIMENTAL AND KINETIC EVALUATION OF PRESSURIZED LEAN PREMIXED HYDROGEN-AIR FLAME STABILITY WITH CARBON DIOXIDE AND STEAM DILUTION
}

\author{
Jon Runyon ${ }^{1 \dagger^{\star}}$, Daniel Pugh ${ }^{1}$, Anthony Giles ${ }^{1}$, Burak Goktepe ${ }^{1}$, Philip Bowen $^{1}$, Richard Marsh ${ }^{1 \dagger}$, Steven Morris ${ }^{1}$ \\ ${ }^{1}$ Cardiff University, Cardiff, Wales, United Kingdom \\ ${ }^{\dagger}$ ASME Member \\ *Corresponding author contact: RunyonJP@cardiff.ac.uk, +44 (0)2920 875931
}

\begin{abstract}
A study has been undertaken to experimentally and numerically evaluate the use of carbon dioxide or steam as premixed fuel additive in hydrogen-air flames to aid in the development of lean premixed (LPM) swirl burner technology for low $\mathrm{NO}_{x}$ operation. Chemical kinetics modelling indicates that the use of $\mathrm{CO}_{2}$ or steam in the premixed reactants reduces $\mathrm{H}_{2}$-air laminar flame speed and adiabatic flame temperature within the well-characterized range of preheated LPM methane-air flames, albeit in markedly different proportions; for example, nearly $65 \% \mathrm{vol} \mathrm{CO}_{2}$ as a proportion of the fuel is required for a reduction in laminar flame speed to equivalent $\mathrm{CH}_{4}$-air values, while approximately $30 \% \mathrm{vol} \mathrm{CO}_{2}$ in the fuel is required for an equivalent reduction in adiabatic flame temperature, significantly impacted by the increased heat capacity of $\mathrm{CO}_{2}$. The $2^{\text {nd }}$ generation high-pressure generic swirl burner, designed for use with $\mathrm{LPM} \mathrm{CH} \mathrm{CH}_{4}$-air, was therefore utilized to experimentally investigate the influence of $\mathrm{CO}_{2}$ and steam dilution on pressurized (up to $250 \mathrm{~kW} / \mathrm{MPa}$ ), preheated (up to $573 \mathrm{~K}$ ), LPM $\mathrm{H}_{2}$-air flame stability using high-speed $\mathrm{OH}^{*}$ chemiluminescence. In addition, exhaust gas emissions, such as $\mathrm{NO}_{x}$ and $\mathrm{CO}$, have been measured in comparison with equivalent thermal power conditions for $\mathrm{CH}_{4}$-air flames, showing that low $\mathrm{NO}_{x}$ operation can be achieved. Furthermore, pure $\mathrm{LPM} \mathrm{H}_{2}$-air flames are characterized for the first time in this burner, stabilized at low equivalence ratio (approximately 0.24) and increased Reynolds number at atmospheric pressure compared to the stable $\mathrm{CH}_{4}$-air flame (equivalence ratio of 0.55 ). The influence of extinction strain rate is suggested to characterize, both experimentally and numerically, the observed lean flame behavior, in particular as extinction strain rate has been shown to be non-monotonic with pressure for highly-reactive and diffuse fuels such as hydrogen.
\end{abstract}

Keywords: Hydrogen, Lean Premixed Combustion, Swirl Flame, Flame Stability, Extinction Strain Rate.

\section{NOMENCLATURE}

$\begin{array}{ll}A F T & \text { Adiabatic Flame Temperature } \\ C C U S & \text { Carbon Capture, Utilization, and Storage } \\ C R Z & \text { Central Recirculation Zone } \\ G T & \text { Gas Turbine } \\ H P G S B-2 & \text { High Pressure Generic Swirl Burner (Mk. II) } \\ L P M & \text { Lean Premixed } \\ N S D & \text { Normalized Standard Deviation } \\ S M R & \text { Steam-Methane Reforming } \\ & \\ I^{\prime}{ }^{\prime} H^{*} & \text { Instantaneous Integral OH* Intensity (a.u.) } \\ I_{O H^{*}} & \text { Mean Integral OH* Intensity (a.u.) } \\ P 2 & \text { Burner Inlet Pressure (MPa) } \\ P_{t h e r m} & \text { Thermal Power (kW) } \\ r & \text { Radial Direction (mm) } \\ R e & \text { Reynold Number } \\ S_{g} & \text { Geometric Swirl Number } \\ S_{L} & \text { Laminar Flame Speed }(\mathrm{cm} / \mathrm{s}) \\ T 2 & \text { Burner Inlet Temperature }(\mathrm{K}) \\ \bar{u} & \text { Mean Nozzle Exit Axial Velocity (m/s) } \\ y & \text { Axial Direction (mm) } \\ \alpha & \text { Thermal Diffusivity (m } / \mathrm{s}) \\ \Delta P & \text { Swirler Pressure Drop }(\% \text { of } P 2) \\ \kappa_{e x t} & \text { Extinction Strain Rate }\left(\mathrm{s}^{-1}\right) \\ \varphi & \text { Equivalence Ratio }\end{array}$

\section{INTRODUCTION}

Industrial gas turbine (GT) manufacturers have committed to increasing hydrogen capability in their engines from $20 \%$ (by volume) in natural gas by 2020 to $100 \%$ hydrogen by 2030 , while also acknowledging the challenges associated with the combustion system related to this fuel shift away from natural gas [1]. In addition to the combustion challenge, the source of $\mathrm{H}_{2}$ for these GTs is currently a source of contention, whether the $\mathrm{H}_{2}$ is "grey" (produced via unabated natural gas reforming), "blue" (produced in conjunction with carbon capture, utilization, and storage, or CCUS), or "green" 
(produced via electrolysis powered by renewable energy). Currently, $76 \%$ of $\mathrm{H}_{2}$ produced globally comes from natural gas, with steam-methane reforming (SMR) the most prevalent technology employed [2]. The International Energy Agency [2] notes that the use of unabated SMR is expected to continue in the short term given favourable economics, however the push for decarbonization of $\mathrm{H}_{2}$ production and the concentrated $\mathrm{CO}_{2}$ by-product stream from SMR make combined SMR-CCUS applications viable under certain market conditions to produce "blue" $\mathrm{H}_{2}$ in large quantities while large-scale, renewable "green" $\mathrm{H}_{2}$ sources are further developed.

The potential for aligning industrial processes, such as SMR for $\mathrm{H}_{2}$ production, with CCUS provides three distinct vectors $\left(\mathrm{H}_{2}\right.$, high purity $\mathrm{CO}_{2}$, or steam generated from waste heat) for utilization in decarbonized gas turbine (GT) power generation, considering both new $\mathrm{H}_{2}$-fired GTs and retrofit of existing GTs. Many GTs utilize dry low- $\mathrm{NO}_{\mathrm{x}}$ burner technology based on the concept of swirl-stabilized lean premixed (LPM) operation for combustion of natural gas, however, research into the use of swirl-stabilized LPM operation for pure or dilute $\mathrm{H}_{2}$ combustion is limited at conditions of elevated burner inlet temperature, $T 2$, and inlet pressure, P2. For example, Stathopoulos et al. [3] evaluated steam dilution for $\mathrm{NO}_{\mathrm{x}}$ abatement of $\mathrm{CH}_{4}-\mathrm{H}_{2}$-air swirl flames at $T 2=673 \mathrm{~K}, P 2$ up to $0.9 \mathrm{MPa}$, and thermal power, $P_{\text {therm }}$, up to $800 \mathrm{~kW}$, however $\mathrm{H}_{2}$ was limited to $10 \%$ vol in $\mathrm{CH}_{4}$. Mayer et al. [4] conducted flashback and lean blowoff stability trials at $T 2=423 \mathrm{~K}, P 2$ up to $0.5 \mathrm{MPa}$, and premixed $\mathrm{H}_{2}$ up to 100 \%vol fuel in blends with $\mathrm{CH}_{4}$, noting in the conclusions that future studies should consider additional diluents to the fuel.

The higher reactivity and diffusivity of $\mathrm{H}_{2}$ [5], compared with methane-based fuels, can lead to undesirable combustion phenomena in practical LPM systems, including flashback (due to increased flame speed) and high $\mathrm{NO}_{\mathrm{x}}$ emissions (due to increased adiabatic flame temperature, AFT) [6,7]. To counteract these effects, a variety of approaches have been considered. In addition to the fuel injection strategies identified by Mayer et al. [4], Reichel et al. [6] investigated LPM swirl-stabilized $\mathrm{H}_{2}$-air flames under elevated temperature and atmospheric pressure, utilizing axial air injection to improve the flashback performance of the burner while maintaining low $\mathrm{NO}_{\mathrm{x}}$ emissions. Strakey et al. [8] found that $\mathrm{H}_{2}$ addition up to $80 \%$ vol in LPM natural gas extends the preheated, pressurized lean blowoff equivalence ratio, $\varphi$, which would in turn help to reduce $\mathrm{NO}_{\mathrm{x}}$ emissions and flashback potential by reducing AFT and laminar flame speed $\left(S_{L}\right)$, respectively. However, operation above $85 \% \mathrm{H}_{2}$ resulted in flashback issues using that particular swirl geometry under those conditions. Other measures taken to address these challenges in $\mathrm{H}_{2}$ flames include non-premixed operation such as micromixing [9], high-momentum jets (e.g. FLOX) [10], or sequential combustion (e.g. Ansaldo Energia's GT-36) [11].

Fuel and/or oxidizer dilution can also be employed to control the reactivity and emissions formation of $\mathrm{H}_{2}$ flames, as shown by Weiland and Strakey [12], who utilized excess $\mathrm{N}_{2}$ for $\mathrm{NO}_{\mathrm{x}}$ control of a $\mathrm{H}_{2}$-air diffusion flame, and Tanneberger et al. [13] who utilized steam dilution for stoichiometric operation of non-premixed $\mathrm{H}_{2}-\mathrm{O}_{2}$ flames. However, both approaches imply air separation as part of the process, incurring an overall system efficiency penalty. If existing or new $\mathrm{H}_{2}$ GTs are located near large-scale SMR $\mathrm{H}_{2}$ production, and furthermore if CCUS systems are installed for $\mathrm{CO}_{2}$ capture from the SMR process, then by-product streams of high-purity $\mathrm{CO}_{2}$ or waste-heat generated steam would be potential available vectors for LPM $\mathrm{H}_{2}$ fuel dilution. This may be particularly attractive to reduce downtime for retrofit on existing LPM GTs designed for use with natural gas, if compatibility can be demonstrated.

Canonical flame studies have been conducted previously with both $\mathrm{CO}_{2}$ and steam dilution of $\mathrm{H}_{2}$, however more practical studies are limited. Masri et al. [14] investigated piloted $\mathrm{H}_{2}-\mathrm{CO}_{2}$ fuel flames in the Sydney burner using a joint Raman-Rayleigh-LIF technique, noting that differential diffusion and the $\mathrm{H}$ radical play a role near lean extinction and also that $\mathrm{CO}_{2}$ may react to give $\mathrm{CO}$. A jet-stirred reactor study by Cong and Dagaut [15] supports this, concluding that $\mathrm{H}_{2}$ oxidation was inhibited by decreased $\mathrm{OH}$ production in the presence of $\mathrm{CO}_{2}$ as it reacts with $\mathrm{H}$ radicals, $\mathrm{CO}_{2}+\mathrm{H}=\mathrm{CO}+\mathrm{OH}$, when adding $30 \% \mathrm{CO}_{2}$ to a lean $\mathrm{H}_{2}-\mathrm{O}_{2}-\mathrm{N}_{2}$ mixture at $\varphi=0.2$. In studies evaluating steam dilution effects on $S_{L}$, both Kuznetsov et al. [16] and Lyu et al. [17] note a nonmonotonic pressure effect (increase followed by decrease with increasing pressure) in $\mathrm{H}_{2}-\mathrm{O}_{2}$ and $\mathrm{H}_{2}$-air mixtures, respectively, with the effect in the latter observed up to $12 \%$ vol $\mathrm{H}_{2} \mathrm{O}$. This has been identified as related to the increased role of third body reactions such as $\mathrm{H}+\mathrm{O}_{2}(+\mathrm{M})=\mathrm{HO}_{2}(+\mathrm{M})$ with increasing pressure [16, 17]. Similar nonmonotonic behaviour of the extinction strain rate, $\kappa_{e x t}$, as a function of pressure was observed by Niemann et al. [18] in a diffusion counterflow flame with $\mathrm{H}_{2}-\mathrm{N}_{2}$ fuel and air as oxidizer, influenced by the same third body reaction noted previously. Furthermore, in a more practical application, steam addition has been shown to limit $\mathrm{NO}_{\mathrm{x}}$ emissions through both thermal and chemical pathways in premixed swirl combustion of high- $\mathrm{H}_{2}$ content fuels under elevated temperature, atmospheric pressure conditions [19].

\subsection{INVESTIGATION AIM}

Given the recent resurgence in interest in $\mathrm{H}_{2}$ use as a fuel for gas turbines alongside renewable power generation, there is a need for further validation of its use in practical LPM burner geometries operating at elevated $T 2$ and $P 2$. To address this gap, this study presents experimental results at elevated temperature for both atmospheric and elevated pressure $\mathrm{H}_{2}$-air, $\mathrm{H}_{2}-\mathrm{CO}_{2}$-air and $\mathrm{H}_{2}-\mathrm{H}_{2} \mathrm{O}$-air flames. A detailed chemical kinetic study supplements the observed experimental measurements, particularly in regards to prediction of stable ignition and operating limits as well as the nonmonotonic pressure effect on pure and dilute $\mathrm{H}_{2}$-air $\kappa_{\text {ext }}$. This study aims to identify and evaluate the influence of fuel diluent fraction and burner operating pressure on the lean stability and emissions of $\mathrm{H}_{2}$-air swirl flames, accomplished primarily through the use of highspeed, time-resolved $\mathrm{OH}^{*}$ chemiluminescence and exhaust gas analysis. This will inform future flame detection methods in $\mathrm{H}_{2}$ GTs and provide a measure of heat release location for CFD model validation with detailed chemistry, given the relative simplicity of $\mathrm{H}_{2}$ chemistry compared with gaseous hydrocarbons. By using LPM swirl burner technology, which is widely deployed for low- $\mathrm{NO}_{\mathrm{x}}$ natural gas applications, the aim is to identify initial conditions required for retrofit of existing GTs to operate on $\mathrm{H}_{2}$. The development of new, low$\mathrm{NO}_{\mathrm{x}}$ LPM $\mathrm{H}_{2}$ combustor designs for use in GTs, a key development need for manufacturers by 2030 [1], will also be aided by the results of this study. 


\section{EXPERIMENTAL AND NUMERICAL APPROACH}

\subsection{GENERIC SWIRL BURNER}

Atmospheric and elevated pressure combustion experiments were conducted in the $2^{\text {nd }}$ generation high-pressure generic swirl burner HPGSB-2, seen in Fig. 1. The HPGSB-2 is well-characterized in terms of its stable operating limits, fuel flexibility, and emissions [20-23]. However, this study presents the first use of LPM pure and diluted $\mathrm{H}_{2}$-air in this burner. Further information regarding this experimental setup can be found in other works [20-23]. The air mass flow rate was measured via Coriolis flow meter (Emerson CMF050) and then heated before fuel and diluent were injected upstream of the "Premixed Inlet" in Fig. 1, where $T 2$ (K-type, $\pm 2.2 \mathrm{~K}$ ) and $P 2$ (Druck PDCR 10/T, $\pm 0.4 \%$ ) were also measured. Fuel and diluent were metered as follows: $\mathrm{CH}_{4}$ (Emerson CMF010), $\mathrm{H}_{2}$ (Bronkhorst M14 mini CORI-FLOW), $\mathrm{CO}_{2}$ (Emerson CMF025), and liquid $\mathrm{H}_{2} \mathrm{O}$ (Bronkhorst M14 mini CORIFLOW) into a steam generator. A radial-tangential swirler was used with a geometric swirl number of $S_{g}=0.8$, with an $18 \mathrm{~mm}$ OD bluff-body lance within the exit nozzle. The swirler pressure drop, $\triangle P$, was measured with a Druck PDCR 10/35L differential pressure transducer $(0.04 \%$ full scale to $70 \mathrm{kPa})$. The burner assembly was installed in a high-pressure optical chamber, which allows visual access using quartz windows and a cylindrical quartz burner confinement [20].

QUARTZ CONFINEMENT

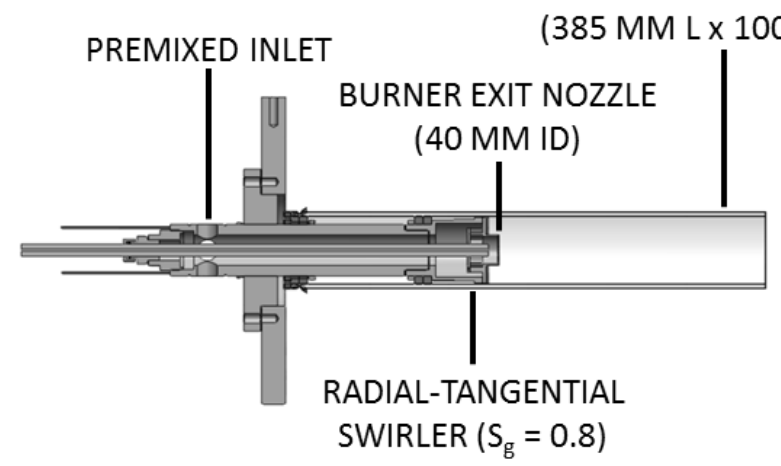

Figure 1. SECTIONED VIEW OF HPGSB-2

\subsection{EXPERIMENTAL CONDITIONS}

All combustion studies were conducted under LPM conditions, with two distinct pressure scalings and burner inlet temperatures: $125 \mathrm{~kW} / \mathrm{MPa}$ at $T 2=523 \mathrm{~K} \pm 5 \mathrm{~K}$ and 250 $\mathrm{kW} / \mathrm{MPa}$ at $T 2=573 \mathrm{~K} \pm 5 \mathrm{~K}$, respectively. Thus, atmospheric pressure experiments, to be discussed first, were conducted at $P_{\text {therm }}=12.5 \mathrm{~kW}$ at $532 \mathrm{~K}$, followed by selected pressurized conditions presented at each scaling given above. Utilizing this scaling method maintains volumetric flow, thus bulk exit velocity from the swirler nozzle, $\bar{u}$, for constant $\varphi$ and diluent fraction as $P 2$ is increased.

For both $\mathrm{CH}_{4}$-air and $\mathrm{H}_{2}$-based flames, the lean operational limit was characterized by flame detachment from the burner exit nozzle and the rich operational limit was characterized by intermittent flame flashback into the burner exit nozzle. Both phenomena were identified by in-situ monitoring of the high-speed $\mathrm{OH}^{*}$ chemiluminescence images. The lean stability limit was identified by intermittent loss of the flame root attached to the burner exit nozzle resulting from small increments in either inlet air (at a fixed fuel dilution rate) DRAFT or diluent flow (with fixed $\varphi$ ). The flashback stability limit was characterized by momentary upstream flame retreat into the burner exit nozzle observed with reduction of inlet air or diluent flow. Neither $\mathrm{CH}_{4}$ nor $\mathrm{H}_{2}$ flame was driven to $\mathrm{LBO}$ (to prevent build-up of unburned fuel in the exhaust) or full flashback (to prevent damage to upstream burner components), both of which are particularly critical for the $\mathrm{H}_{2}$ cases at elevated pressure.

Table 1 provides the experimental conditions employed in this study. For the dilute $\mathrm{H}_{2}$ conditions, the premixed fuel dilution rate is presented as "\%vol $\mathrm{H}_{2} \mathrm{O}$ Fuel" and "\%vol $\mathrm{CO}_{2}$ Fuel" per Equations 1.a and 1.b, respectively. For example, the designation " $50 \mathrm{H}_{2}-50 \mathrm{CO}_{2}$ " represents an equal molar concentration of $\mathrm{H}_{2}$ and $\mathrm{CO}_{2}$ in the full premixed reactants. The swirler pressure drop, $\Delta P$, is presented as a percentage of $P 2$ with the highest pressure drop observed for the $250 \mathrm{~kW} / \mathrm{MPa}$ condition with $\mathrm{H}_{2}-\mathrm{CO}_{2}$ fuel.

Table 1. EXPERIMENTAL CONDITIONS IN THE HPGSB-2

\begin{tabular}{|c|c|c|c|c|c|}
\hline Fuel & $\begin{array}{r}T 2 \\
( \pm 5 \mathrm{~K}) \\
\end{array}$ & $\begin{array}{c}\text { P2 } \\
\text { (MPa) }\end{array}$ & $\begin{array}{l}\mathbf{P}_{\text {therm }} \\
(\mathbf{k W})\end{array}$ & $\varphi$ & $\Delta P(\%)$ \\
\hline $\mathrm{CH}_{4}$ & 523 & 0.11 & 12.5 & $0.49-0.80$ & $0.1-0.3$ \\
\hline $\mathrm{H}_{2}$ & 523 & 0.11 & 12.5 & $0.21-0.25$ & $0.8-1.1$ \\
\hline $\begin{array}{c}\mathrm{H}_{2^{-}} \\
\mathrm{H}_{2} \mathrm{O}\end{array}$ & 523 & $\begin{array}{l}0.11- \\
0.15\end{array}$ & $\begin{array}{c}12.5- \\
18.75\end{array}$ & $0.25-0.35$ & $0.6-0.9$ \\
\hline $\begin{array}{l}\mathrm{H}_{2^{-}} \\
\mathrm{CO}_{2}\end{array}$ & $\begin{array}{c}523- \\
573\end{array}$ & $\begin{array}{l}0.11- \\
0.275\end{array}$ & $\begin{array}{c}12.5- \\
68.75\end{array}$ & $0.25-0.40$ & $\begin{array}{c}0.7- \\
4.5\end{array}$ \\
\hline
\end{tabular}

$$
\begin{aligned}
& \% \text { vol } \mathrm{H}_{2} \mathrm{O} \text { Fuel }=\frac{\left(\% \text { vol } \mathrm{H}_{2} \mathrm{O}\right)_{\text {premix }}}{\left(\% \text { vol } \mathrm{H}_{2} \mathrm{O}\right)_{\text {premix }}+\left(\% \text { vol } \mathrm{H}_{2}\right)_{\text {premix }}} \\
& \% \text { vol } \mathrm{CO}_{2} \text { Fuel }=\frac{(\% \text { vol CO})_{\text {premix }}}{(\% \text { vol CO})_{\text {premix }}+\left(\% \text { vol } \mathrm{H}_{2}\right)_{\text {premix }}}
\end{aligned}
$$

\subsection{EXPERIMENTAL DIAGNOSTICS}

\subsubsection{TIME-RESOLVED OH* CHEMILUMINESCENCE}

Time-resolved $\mathrm{OH}^{*}$ chemiluminescence images were captured for each experimental condition system at $90^{\circ}$ relative to the axial flow direction. Measurements focused on the wellknown $\mathrm{A}^{2} \Sigma^{+}-\mathrm{X}^{2} \Pi \mathrm{OH}^{*}$ peak at $309 \mathrm{~nm}$ [24] using a $315 \mathrm{~nm}$ $( \pm 15 \mathrm{~nm}$ FWHM) bandpass filter. This ultraviolet system was selected due to the limited visible spectra emitted by the dilute $\mathrm{H}_{2}$ flames, as normal visible bands available in $\mathrm{CH}_{4}$-air flames resulting from $\mathrm{CH}^{*}, \mathrm{C}_{2} *$, and broadband $\mathrm{CO}_{2} *$ emission are not present in $\mathrm{H}_{2}$-air and $\mathrm{H}_{2}-\mathrm{H}_{2} \mathrm{O}$-air flames and are very limited to certain dilution rates for $\mathrm{H}_{2}-\mathrm{CO}_{2}$-air flames.

$\mathrm{OH}^{*}$ measurements were made with an intensified high-speed CMOS camera system as detailed in [21]. The system was operated at $4000 \mathrm{~Hz}$, with an intensifier gate time of $10 \mu \mathrm{s}$ and constant gain. The image resolution of 4.6 pixels $/ \mathrm{mm}$ results in a field of view of $75 \mathrm{~mm}$ (axial, $y$ ) x 100 $\mathrm{mm}$ (radial, $r$ ) relative to the edge and centreline of the burner exit nozzle, respectively. For averaged images, each instantaneous $\mathrm{OH}^{*}$ chemiluminescence image was filtered using a 3x3 pixel median filter and background-corrected before being temporally-averaged from 2000 images. The temporally-averaged images were then processed using an Abel inversion algorithm [20]. Temporal variation of the $\mathrm{OH}^{*}$ chemiluminescence signal was evaluated using a pixel-wise normalized standard deviation (NSD, equal to the quotient of 
pixel intensity standard deviation and mean pixel intensity) calculated from each set of 2000 instantaneous images, where unity values indicate regions of high intensity fluctuation. Mean and instantaneous integral intensity, $I I_{O H^{*}}$ and $I I^{\prime}{ }_{O H^{*}}$ [20] respectively, were also evaluated.

\subsubsection{EXHAUST GAS ANALYSIS}

Exhaust gas sampling and analysis were conducted using an industry standard system detailed in [21-23], with the addition of $\mathrm{CO}$ measurements. Total $\mathrm{NO}_{\mathrm{x}}$ concentrations were measured hot and wet to avoid any losses, with data presented at the equivalent dry conditions using an equilibrium $\mathrm{H}_{2} \mathrm{O}$ molar fraction from Chemkin-Pro [25]. For $\mathrm{CO}$ measurements, a chiller reduces the exhaust molar $\mathrm{H}_{2} \mathrm{O}$ concentration to $<1 \%$. Dry $\mathrm{CO}$ concentrations were measured using a nondispersive infrared analyzer (Signal Instruments 9000MGA), calibrated in the range 0-904 ppmV. Both $\mathrm{NO}_{\mathrm{x}}$ and $\mathrm{CO}$ emissions were normalized to $15 \% \mathrm{O}_{2}$ concentration as in [21], using exhaust molar $\mathrm{O}_{2}$ measurements. Typical uncertainty of $\sim 5 \%$ of measurement accounts for analyzer specifications, linearization, and accuracy in span gas certification.

\subsection{CHEMICAL KINETICS MODELLING}

A parametric chemical kinetics modelling study was conducted using Chemkin-Pro [25] to supplement the observed experimental phenomena. Two reaction mechanisms were used: GRI-Mech 3.0 [26] for $\mathrm{CH}_{4}$-air and the $\mathrm{H}_{2}$ mechanism from $\mathrm{Li}$ et al. [27] for all $\mathrm{H}_{2}$-based conditions with $\mathrm{N}_{2}$ as the bath gas. The equilibrium program was used to model AFT and equilibrium exhaust $\mathrm{H}_{2} \mathrm{O}$ concentrations for use in normalizing wet emissions measurements to equivalent dry conditions [22]. The PREMIX program was used to calculate laminar flame speeds, $S_{L}$, based on a freely propagating flame model. Solutions in this model were based on an adaptive grid of 1000 points, with mixture-averaged transport properties and trace series approximation. Finally, the OPPDIF program was used to evaluate $\kappa_{e x t}$ for consideration in its use as a predictor of lean flame stability and flame stabilization location [28]. The model was based on twin premixed fuel/air jets in opposition and included the use of multi-component diffusion coefficients and Soret effects. This is similar to the method used by Shanbhogue et al. [28] in a burner of similar swirl geometry $\left(S_{g}\right.$ $=0.7$ [28] vs 0.8 in this work), Reynolds number $\left(2 \times 10^{4}\right.$ [28] vs $1.5 \times 10^{4}-2 \times 10^{4}$ ) and up to $20 \% \mathrm{H}_{2}$ in $\mathrm{CH}_{4}$.

\section{RESULTS AND DISCUSSION}

\subsection{CHEMICAL KINETICS MODELLING}

\subsubsection{ATMOSPHERIC PRESSURE}

Given that the HPGSB-2 was designed for use with $\mathrm{CH}_{4}$, the initial chemical kinetic study undertaken aimed to identify an appropriate dilute $\mathrm{H}_{2}$ blend to allow for successful LPM ignition. This was accomplished by identifying the fuel diluent concentration required to reduce the laminar flame speed, $S_{L}$, of the $\mathrm{H}_{2}$ blend within the stable ignition range for LPM $\mathrm{CH}_{4}$-air at $\varphi=0.6$ with $T 2=523 \mathrm{~K}$ and $P 2=0.11 \mathrm{MPa}$. The results are shown in Fig. 2. The dilution rate required for LPM ignition at similar $S_{L}$ to $\mathrm{CH}_{4}$-air flames is approximately $35 \mathrm{H}_{2}-65 \mathrm{CO}_{2}$ and $30 \mathrm{H}_{2}-70 \mathrm{H}_{2} \mathrm{O}$, respectively.

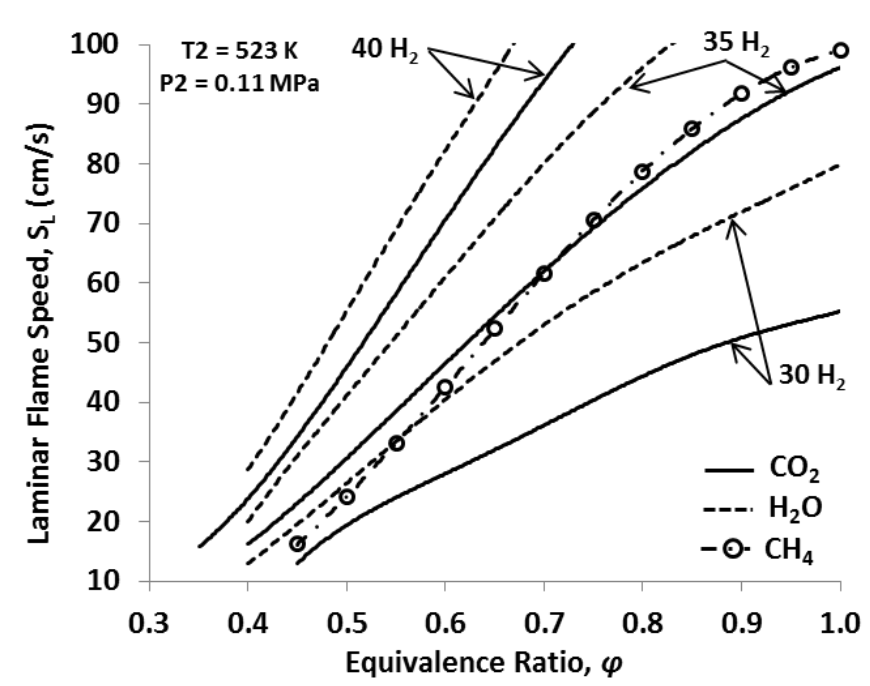

Figure 2. $\mathrm{S}_{\mathrm{L}} \mathrm{OF} \mathrm{CH}_{4}$-AIR, $\mathrm{H}_{2}-\mathrm{CO}_{2}$-AIR, AND $\mathrm{H}_{2}-\mathrm{H}_{2} \mathrm{O}$-AIR MIXTURES WITH VARYING DILUENT CONTENT

Other important trends are also identified: 1) $S_{L}$ of $\mathrm{H}_{2} \mathrm{O}$ dilute $\mathrm{H}_{2}$-air flames is consistently higher than with $\mathrm{CO}_{2}$ dilution and 2) the rate at which $S_{L}$ decreases with increasing dilution is more evident with $\mathrm{CO}_{2}$ dilution than with $\mathrm{H}_{2} \mathrm{O}$ dilution. This second trend suggests that stable operation at higher equivalence ratios may be possible with $\mathrm{CO}_{2}$ dilution, therefore yielding the benefits of reduced excess air (and thus $\mathrm{N}_{2}$ content for $\mathrm{NO}_{\mathrm{x}}$ formation) along with increasing the product $\mathrm{CO}_{2}$ concentration for potential recovery via CCUS.

Furthermore, as will be discussed in Section 3.2.1, pure and dilute $\mathrm{H}_{2}$-air swirl flames could be stabilized below $\varphi$ $=0.3$, which appears to be very near the convergence limit of the $\mathrm{Li}$ et al. [27] mechanism, underscoring the catalytic influence that turbulence and diffusivity have on swirl flame stabilization which cannot be captured by the laminar flame model. This also highlights a limitation of the mechanism in regards to ultra-lean, highly dilute $\mathrm{H}_{2}$ mixtures.

The parametric chemical kinetic modelling study was further expanded to evaluate the influence of fuel diluent fraction on key stability and emissions indicators: $S_{L}$, AFT, and $\kappa_{e x t}$ for all lean equivalence ratios $(\varphi \leq 1)$ at $T 2=523 \mathrm{~K}$ and $P 2$ $=0.11 \mathrm{MPa}$. The results are presented in Fig. 3, with $S_{L}$, AFT, and $\kappa_{\text {ext }}$ plotted against \%Fuel Diluent for $\mathrm{CO}_{2}(\mathrm{a}, \mathrm{b}$, and $\mathrm{c}$, respectively) and $\mathrm{H}_{2} \mathrm{O}(\mathrm{d}$, e, and $\mathrm{f}$, respectively). Similar to the approach taken in Fig. 2, reference values are also plotted for a $\mathrm{CH}_{4}$-air flame without dilution at a stable burner operating condition $(\varphi=0.6)$, specifically $S_{L}=42.6 \mathrm{~cm} / \mathrm{s}, \mathrm{AFT}=1834 \mathrm{~K}$, and $\kappa_{\text {ext }}=329 \mathrm{~s}^{-1}$. The trend observed in Fig. 2, namely the reduction rate in $S_{L}$ with increased $\mathrm{CO}_{2}$ dilution compared with $\mathrm{H}_{2} \mathrm{O}$ dilution, is more evident in Figures 3.a and 3.d, particularly above $60 \%$ Fuel $\mathrm{CO}_{2}$ and $\varphi=0.5$. To achieve the same $S_{L}$ as the $\mathrm{CH}_{4}$-air flame at $\varphi=0.6$, a pure $\mathrm{H}_{2}$-air flame would have to be operated slightly above $\varphi=0.3$, while $66 \%$ Fuel $\mathrm{CO}_{2}$ and $69 \%$ Fuel $\mathrm{H}_{2} \mathrm{O}$ dilution would be required to achieve the same $S_{L}$ at $\varphi=0.6$. This represents almost an order of magnitude reduction in $S_{L}$ from the pure $\mathrm{H}_{2}$-air $S_{L}$ at $\varphi=0.6$, which emphasizes the reactivity of lean $\mathrm{H}_{2}$-air flames, even at high dilutions rates. A similar trend regarding the rate of reduction of AFT is observed in Figures 3.b and 3.e, with $\mathrm{CO}_{2}$ dilution shown to increase the rate of reduction compared with $\mathrm{H}_{2} \mathrm{O}$, particularly above $\varphi=0.6$. 
Whereas quite high $(>65 \%) \mathrm{H}_{2}$ dilution would be required for an equivalent reduction in $S_{L}$ to $\mathrm{CH}_{4}$-air values, significantly less diluent is required for an equivalent reduction in AFT, namely $33 \%$ Fuel $\mathrm{CO}_{2}$ and $37 \%$ Fuel $\mathrm{H}_{2} \mathrm{O}$ at $\varphi=0.6$. This is due mainly to the increased specific heat capacity of $\mathrm{CO}_{2}$ relative to steam and $\mathrm{N}_{2}, 21 \%$ and $34 \%$ higher at $523 \mathrm{~K}$, respectively. This difference between dilution rates for reduction in $\mathrm{H}_{2}$-air $S_{L}$ and AFT to $\mathrm{CH}_{4}$-air values suggests that modifications to the burner operating regime or design may be required to achieve useful burner exit temperatures while avoiding flashback. This would include higher total mass flow rate through the burner, resulting in higher $\bar{u}$, to the potential detriment of increased $\Delta P$, as shown in Table 1, unless burner geometry is redesigned. To enable more straightforward retrofit applications, operation of $\mathrm{H}_{2}$-based fuels at lower

(a) $\mathrm{S}_{\mathrm{L}}$ of $\mathrm{H}_{2}$ - $\mathrm{CO}_{2}$-air

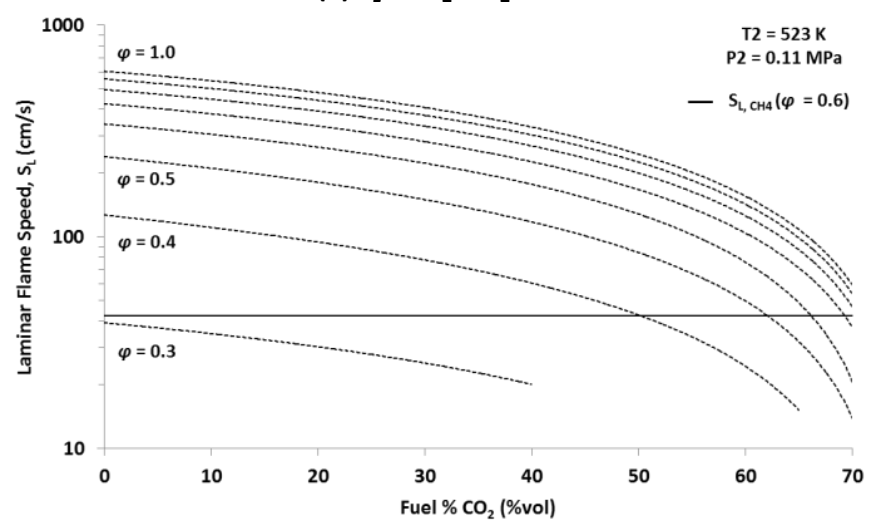

(b) AFT of $\mathrm{H}_{2}$ - $\mathrm{CO}_{2}$-air

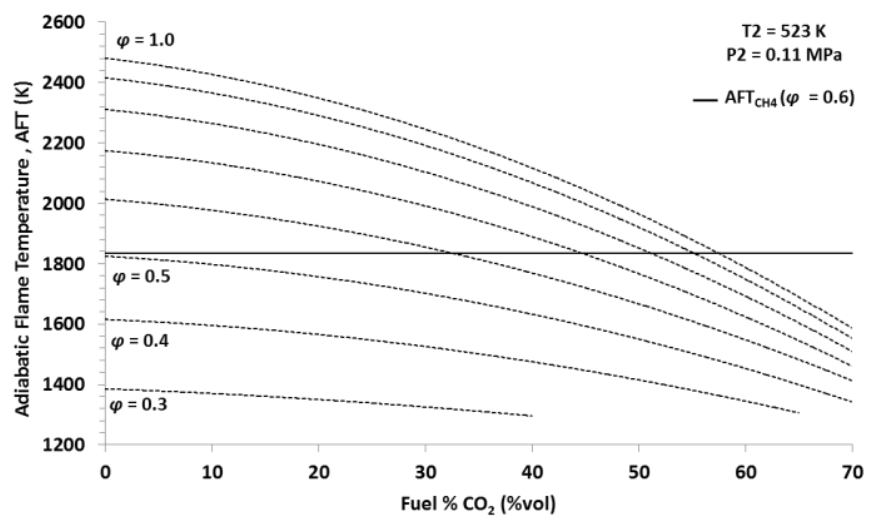

(c) $\kappa_{\text {ext }}$ of $\mathrm{H}_{2}$ - $-\mathrm{CO}_{2}$-air

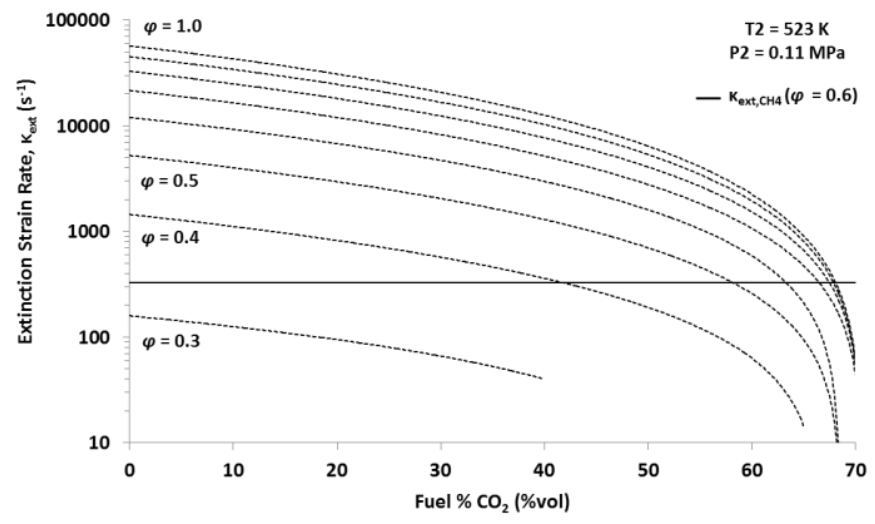

thermal power (e.g. part load) may be required to maintain existing burner geometry and design $\Delta P$.

Finally, $\kappa_{e x t}$ modelling is presented in Figures 3.c and 3.f, showing a stronger dependence on $\varphi$ than $S_{L}$, with pure $\mathrm{H}_{2^{-}}$ air $\kappa_{\text {ext }}$ reducing nearly three orders of magnitude from $\varphi=1.0$ to $\varphi=0.3$. This fundamental parameter has been used to identify $\mathrm{CH}_{4}-\mathrm{H}_{2}$ flame stabilization regimes for lean operation in highly strained, turbulent flows [28]. The application of this technique is extended here to consider if $\kappa_{\text {ext }}$ of ultra-lean pure and dilute $\mathrm{H}_{2}$-air can be utilized to indicate flame stability, in particular as $\mathrm{Hu}$ et al. [29] have identified that high $\mathrm{H}_{2}$-content fuels exhibit negative Markstein lengths under LPM conditions. Negative Markstein lengths indicate an increase in $\mathrm{H}_{2}$ flame speed with increasing stretch rate. This behaviour is noted as being impacted significantly by preferential fuel diffusion under lean conditions [29].

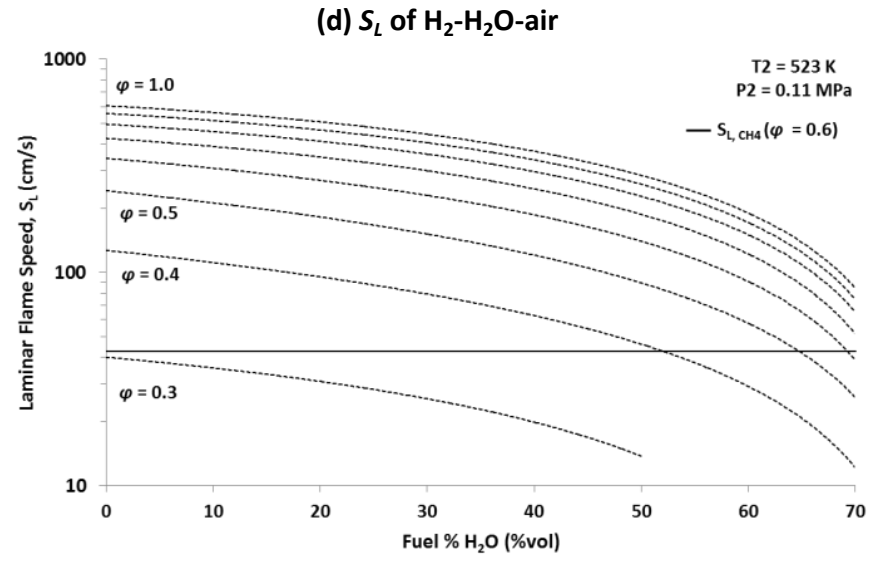

(e) AFT of $\mathrm{H}_{2}-\mathrm{H}_{2} \mathrm{O}$-air

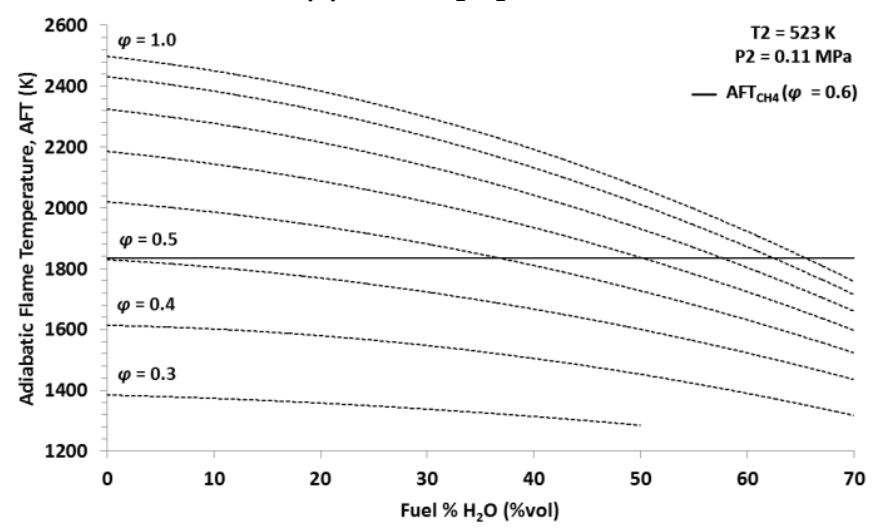

(f) $\kappa_{e x t}$ of $\mathrm{H}_{2}-\mathrm{H}_{2} \mathrm{O}$-air

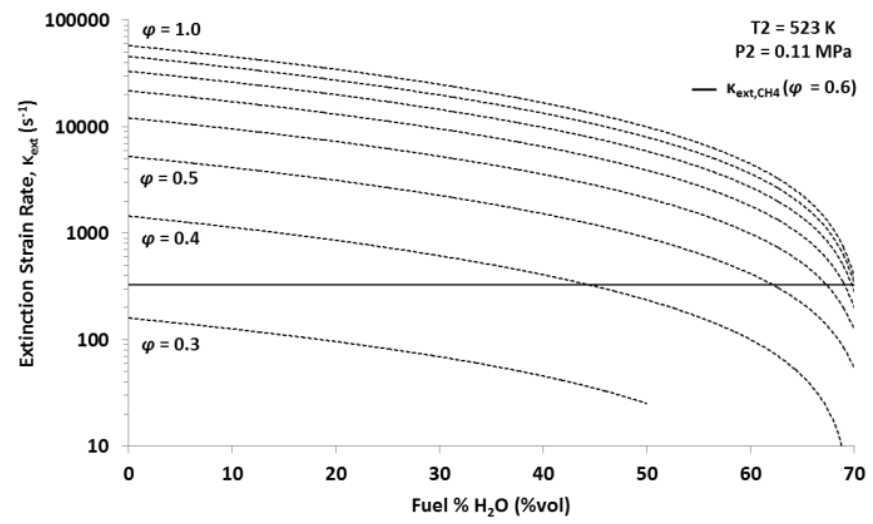

Figure 3. INFLUENCE OF $\mathrm{H}_{2}$ FUEL DILUTION ON MODELLED $S_{L}$, AFT, AND $\kappa_{\text {ext }}$ 
In general, $\kappa_{e x t}$ is higher for the $\mathrm{H}_{2} \mathrm{O}$-diluted cases than the $\mathrm{CO}_{2}$-diluted cases. Similar behaviour between $S_{L}$ and $\kappa_{e x t}$ is seen in regards to reduction rate with diluent addition, with $63 \%$ Fuel $\mathrm{CO}_{2}$ and $67 \%$ Fuel $\mathrm{H}_{2} \mathrm{O}$ required to achieve an equivalent reduction to $\mathrm{CH}_{4}$-air values at $\varphi=0.6$. The similarities in fuel dilution effects on $S_{L}$ and $\kappa_{\text {ext }}$ are to be expected as the simple strained flame extinction is driven by a chemical timescale that incorporates both $S_{L}$ and the gas thermal diffusivity, $\alpha$, which was included in the $\kappa_{\text {ext }}$ calculation (Soret effects) with $\alpha_{\mathrm{CO} 2}<\alpha_{\mathrm{H} 2 \mathrm{O}}$ at $T 2=523 \mathrm{~K}$ [30].

\subsubsection{ELEVATED PRESSURE}

The chemical kinetic modelling of $\kappa_{e x t}$ was broadened to consider elevated pressure effects, particularly given the elevated pressure LPM conditions explored in this study and the experimental observations by Niemann et al. [18] discussed in Section 1. Whereas Niemann et al. [18] measured and modelled $\kappa_{\text {ext }}$ for diffusion $\mathrm{H}_{2}-\mathrm{N}_{2}$-air counterflow flames, the modelling presented in Fig. 4 incorporates pure and dilute (50 \%vol Fuel Diluent) $\mathrm{LPM} \mathrm{H}_{2}$-air and $\mathrm{CH}_{4}$-air at $T 2=523 \mathrm{~K}$ and $\varphi=0.6$. A similar nonmonotonic trend is observed here, with maximum $\kappa_{e x t}$ for pure $\mathrm{H}_{2}$-air at $0.7 \mathrm{MPa}$. This maximum peak reduces by an order of magnitude in the dilute $\mathrm{H}_{2}$ cases, while also shifting to lower pressures, $0.2 \mathrm{MPa}$ for $\mathrm{H}_{2} \mathrm{O}$ and 0.125 $\mathrm{MPa}$ for $\mathrm{CO}_{2}$. This shift in $\kappa_{e x t}$ is expected to influence lean flame stabilization when increasing burner operating pressure, and suggests that the flame may stabilize in different regions of aerodynamic strain within the flow field, critical for avoiding flame flashback during GT operation with $\mathrm{H}_{2}$-based fuels.

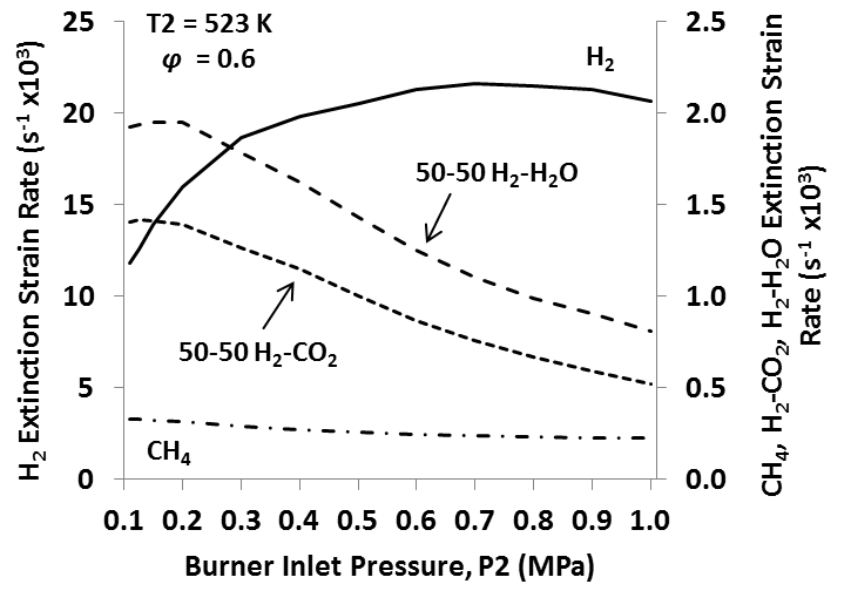

Figure 4. $\kappa_{\text {ext }}$ AS A FUNCTION OF BURNER PRESSURE

\subsection{SWIRL FLAME STABILITY AND EMISSIONS}

\subsubsection{ATMOSPHERIC PRESSURE STABILITY (12.5 kW)}

Burner operation was first examined at atmospheric pressure $(P 2=0.11 \mathrm{MPa})$, elevated temperature $(T 2=523 \mathrm{~K})$, and constant fuel flow $\left(P_{\text {therm }}=12.5 \mathrm{~kW}\right)$. To identify the influence of $\mathrm{H}_{2}$ dilution on flame stability, two parametric operations were undertaken individually. First, diluent flow in the premixed reactants was varied at a fixed $\varphi$ until either flame liftoff or intermittent flashback was observed, or in very lean cases, the diluent flow could be reduced completely to yield a pure $\mathrm{H}_{2}$-air flame. Second, at selected fixed dilution ratios, $\varphi$ was varied by manipulating the air flow. These operations yield the stability curves and stability map shown in Figures 5.a and 5.b, respectively. (a)

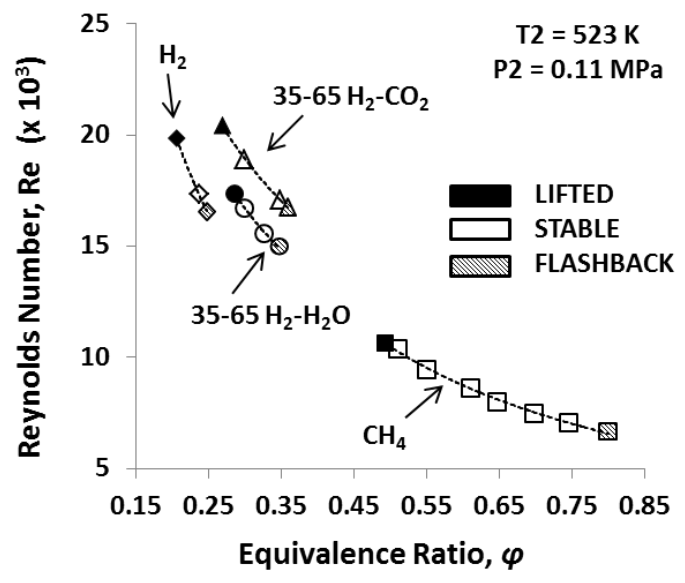

(b)

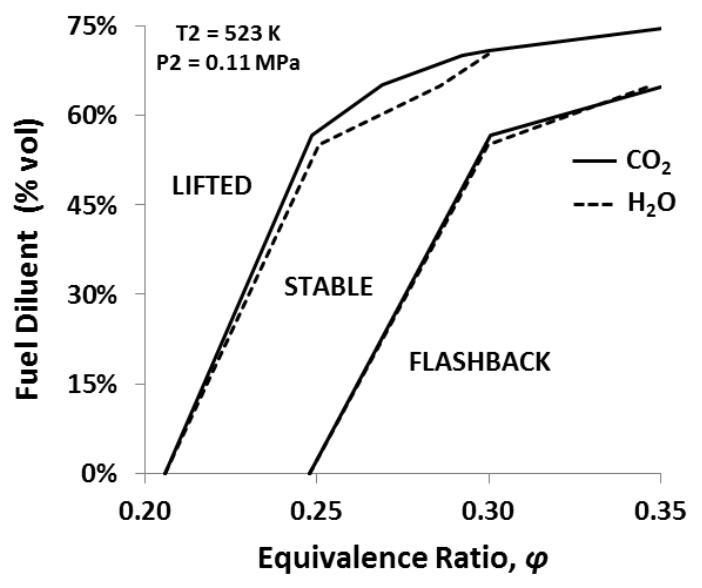

Figure 5. 12.5 kW FLAME STABILITY MAPS AS A FUNCTION OF $\varphi$ AND (a) REYNOLDS NUMBER (CLOSED = LIFTED, OPEN = STABLE, HASHED = FLASHBACK) OR (b) \% FUEL DILUENT

In Figure 5.a, the 35-65 $\mathrm{H}_{2}$-diluent blend, identified by chemical kinetic modelling (see Section 3.1.1) to yield similar $S_{L}$ and $\kappa_{e x t}$ to an equivalent $\mathrm{CH}_{4}$-air flame, is used as a basis to emphasize the influence that $\mathrm{H}_{2}$ has on flame stability, even under highly dilute conditions. Stable operation in this burner requires higher bulk flow through the burner, and thus higher exit velocities from the swirler nozzle, when replacing $\mathrm{CH}_{4}$ with $\mathrm{H}_{2}$. This results in a stable flame $\bar{u}$ that is approximately twice $(\bar{u}=15-20 \mathrm{~m} / \mathrm{s})$ that for a stable $\mathrm{CH}_{4}$-air flame $(\bar{u}=6-9$ $\mathrm{m} / \mathrm{s})$, and thus the stable Reynolds number $(R e)$ doubles as well. The stable operating window is also affected by $\mathrm{H}_{2}$ replacement, both narrowing and shifting to leaner $\varphi$ as compared with the $\mathrm{CH}_{4}$-air flame. As seen in both Figures 5.a and 5.b, operation with $\mathrm{CO}_{2}$ diluent extends the stable operating range of $\mathrm{H}_{2}$ flames compared with pure $\mathrm{H}_{2}$-air and steamdiluted $\mathrm{H}_{2}$-air. This is influenced particularly by the increased dynamic viscosity of $\mathrm{CO}_{2}$ compared to $\mathrm{H}_{2} \mathrm{O}$ at these conditions, which serves to increase levels of turbulence (e.g. $R e$ ) for the same $\bar{u}$, enhancing $\mathrm{H}_{2}$ flame propagation. Operation with pure $\mathrm{H}_{2}$-air was achieved, bounded by a detached flame at $\varphi=0.206$ and intermittent flashback at $\varphi=0.248$. At this low thermal

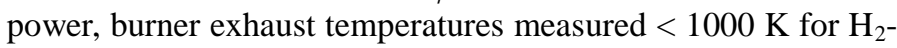
based flames, influenced by the high dilution levels and heat losses to the experimental rig, evidenced by $\mathrm{CH}_{4}$-air flame exhaust temperature at the highest equivalence ratio $(\varphi=0.8)$, 
which measured only about $200 \mathrm{~K}$ higher. Furthermore, as described by Amato et al. [31], high $\mathrm{CO}_{2}$ and $\mathrm{H}_{2} \mathrm{O}$ dilution at low operating pressure will enhance radiative heat losses compared with $\mathrm{O}_{2}$ or $\mathrm{N}_{2}$. Initial studies at higher $P_{\text {therm }}(25 \mathrm{~kW})$ for atmospheric pressure conditions suggest extension of the $\mathrm{H}_{2}$-air stable operating range. This is attributed to increased $\bar{u}$ as a result of increased mass flow, which makes the flame more resistant to flashback and also results in elevated burner exit temperatures, however $\Delta P$ is increased. This will be the subject of future study.

As shown in Fig. 5b, for increasing $\varphi$, the achievable $\mathrm{CO}_{2}$ or $\mathrm{H}_{2} \mathrm{O}$ dilution increases, as the increased $\mathrm{H}_{2}$ flame speed is offset by the physical and chemical effects of the diluents, however the stable operation range narrows. In both the $\mathrm{CO}_{2}$ and steam dilution cases, the widest operating range is achieved at $\varphi=0.25$, which is therefore selected for pressurized conditions detailed in Sections 3.2.2 and 3.2.3.

Abel-transformed $\mathrm{OH}^{*}$ chemiluminescence images are presented in Fig. 6 for selected stable conditions plotted in Fig. 5.a. The Abel transformation is based on an assumption that the flame is axisymmetric about the burner centreline, thus for simplicity, only one half of the flame is shown (with flow from bottom to top) and the false colormap normalized to the maximum for each individual image. Figure 6.a provides a reference $\mathrm{CH}_{4}$-air flame at $\varphi=0.6$, as used in the chemical kinetics modelling, along with three stable $\mathrm{H}_{2}$-based flames: pure $\mathrm{H}_{2}$-air (Fig. 6.b), $35 \mathrm{H}_{2}-65 \mathrm{CO}_{2}$ (Fig. 6.c) and $35 \mathrm{H}_{2}-65 \mathrm{H} 2 \mathrm{O}$ (Fig. 6.d), with the conditions selected at near-equivalent bulk exit velocity, $\bar{u}=17.7 \mathrm{~m} / \mathrm{s} \pm 2 \%$. All flames are seen to stabilize along the shear layer of low axial velocity between the CRZ and outer recirculation zone, as has been shown previously for this burner [20].

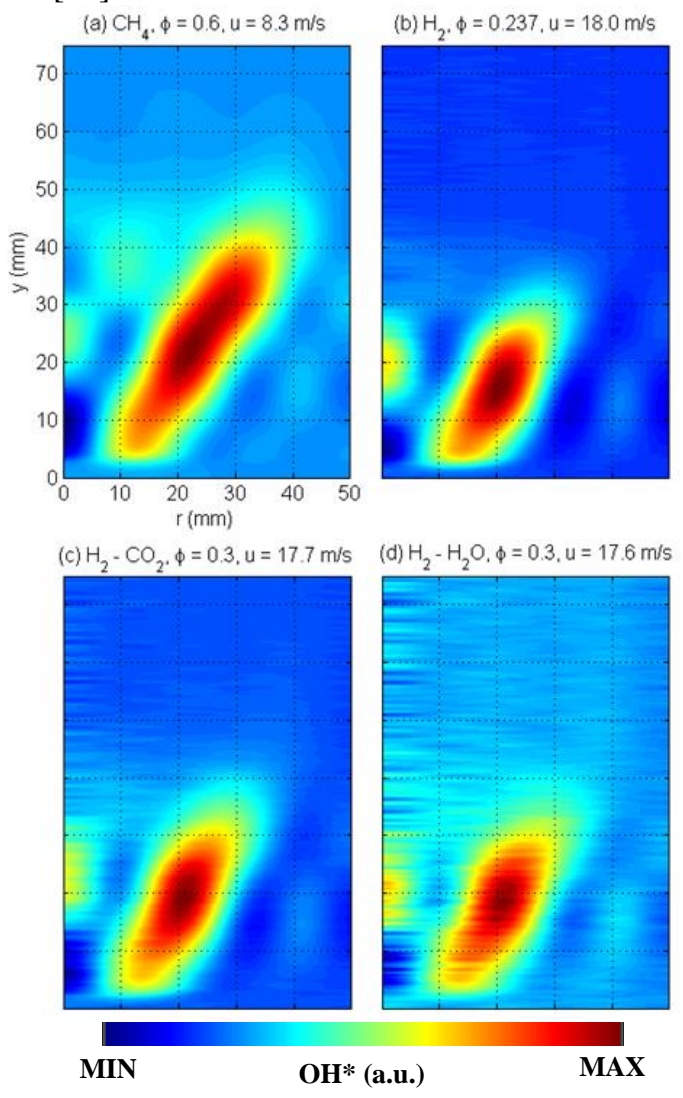

Figure 6. ABEL-TRANSFORMED OH* OF STABLE $12.5 \mathrm{~kW}$ FLAMES: (a) $\mathrm{CH}_{4}$, (b) $\mathrm{H}_{2}$, (c) $35 \mathrm{H}_{2}-65 \mathrm{CO}_{2}$ and (d) $35 \mathrm{H}_{2}-65 \mathrm{H}_{2} \mathrm{O}$
Even under high amounts of air and premixed reactant dilution, the $\mathrm{H}_{2}$-based flames are significantly more compact than the $\mathrm{CH}_{4}$-air flame; this is despite the chemical kinetics modelling predicting lower $S_{L}$, AFT, and $\kappa_{e x t}$ for these conditions. These predictions would imply lower reactivity than the $\mathrm{CH}_{4}$-air flame, however, do not necessarily account for the influence of increased turbulence and diffusivity, resulting in an increased flame propagation speed as the $\mathrm{H}_{2}$-based flame is subjected to increased stretch, as shown by $\mathrm{Hu}$ et al. [29].

Both dilute $\mathrm{H}_{2}$-air flames have a similar bulk shape, slightly less compact than the pure $\mathrm{H}_{2}$-air flame, however the flames vary significantly in terms of absolute $\mathrm{OH}^{*}$ intensity, as seen in Fig. 7. Figure 7 provides a moving average (period $=$ 20 samples) plot of the time-varying $\mathrm{OH}^{*}$ integral intensity, $I^{\prime}{ }_{O H^{*}}$, for 2000 images along with the mean $\mathrm{OH}^{*}$ integral intensity, $I I_{O H^{*}}$, calculated for each dataset. These flame images were captured at the $\mathrm{H}_{2}$-based conditions in Fig. 6. These quantities have been shown to be good qualitative measures of LPM flame heat release [20], and the time-varying signal can provide indications of flame instabilities (e.g. localized extinction may result in a reduction in $\mathrm{II}_{\mathrm{OH}^{*} \text { ). }}$

It should be noted that $\mathrm{CH}_{4}$-air $I_{\mathrm{OH}^{*}}$ at $\varphi=0.6$ is an order of magnitude higher than the pure $\mathrm{H}_{2}$-air values here given the higher AFT and contribution from broadband $\mathrm{CO}_{2}{ }^{*}$ chemiluminescence, which may also be contributing in the $\mathrm{H}_{2-}$ $\mathrm{CO}_{2}$ case. The reduction in $\mathrm{II}^{\prime}{ }_{\mathrm{OH}}^{*}$ from pure $\mathrm{H}_{2}$-air to $\mathrm{H}_{2}-\mathrm{CO}_{2}$ to $\mathrm{H}_{2}-\mathrm{H}_{2} \mathrm{O}$ is suggested in the first instance related to a reduction in heat release with $\mathrm{CO}_{2}$ dilution, and this corresponds to a measured reduction in the burner exit temperature. However, the reduction in $\mathrm{II}^{\prime} \mathrm{OH}^{*}$ from $\mathrm{H}_{2}-\mathrm{CO}_{2}$ to $\mathrm{H}_{2}-\mathrm{H}_{2} \mathrm{O}$ was more surprising, given that $\mathrm{H}_{2}-\mathrm{H}_{2} \mathrm{O}$ AFT is $38 \mathrm{~K}$ higher than $\mathrm{H}_{2}-\mathrm{CO}_{2}$ AFT under these conditions and measured exhaust temperatures were also higher. This suggests that the production of $\mathrm{OH}^{*}$ may be chemically limited in the $\mathrm{H}_{2}-\mathrm{H}_{2} \mathrm{O}$ case, and warrants further investigation.

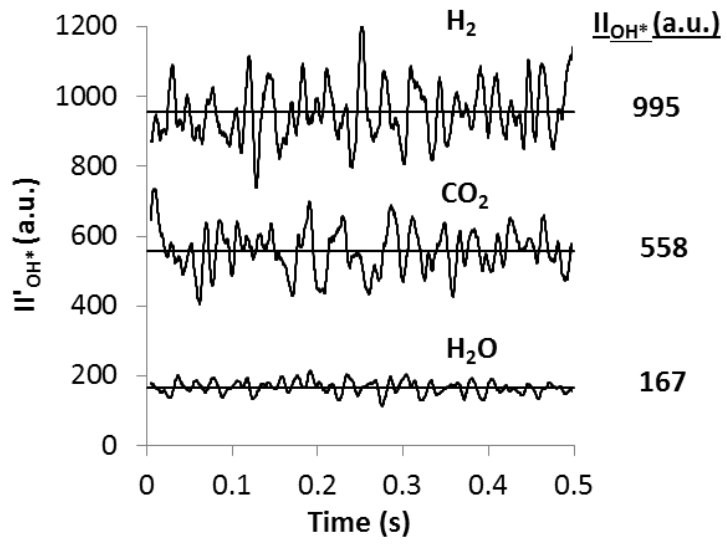

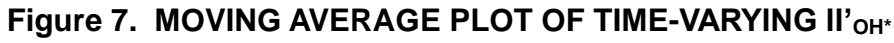
FOR PURE AND DILUTE H2-AIR FLAMES (FROM FIG. 6) WITH MEAN IIOH* $^{*}$ PLOTTED FOR ORIGINAL RAW DATA

In contrast to the spatially-integrated $I^{\prime}{ }^{\prime} H^{*}$ measurement, the NSD plot provides spatial resolution of the temporally-varying $\mathrm{OH}^{*}$ chemiluminescence intensity fluctuation, which is of particular importance for identifying flame liftoff from the burner exit nozzle. The NSD plot provides a measure of $\mathrm{OH}^{*}$ intensity stability. For example, intermittent flame detachment from the swirler exit nozzle would subject the pixels in that region to high intensity 
fluctuations, thus increasing the collated pixel standard deviation relative to the mean pixel intensity. This is evident in Fig. 8 which provides NSD plots for one-half of the pure $\mathrm{H}_{2}$-air flames. Figure 8.a is calculated from the stable condition at $\varphi=$ 0.237 (refer to corresponding time-averaged image in Fig. 6.b), Fig. 8.b is calculated from the lifted flame condition at $\varphi=$ 0.206, and Fig. 8.c is calculated as the lifted flame image NSD normalized to the stable flame image NSD. It must be noted that these plots are formed from the instantaneous, backgroundcorrected $\mathrm{OH}^{*}$ chemiluminescence images and as such are lineof-sight integrated, which gives a bulk conical flame appearance for this swirl burner rather than the pseudo-planar representation resulting from Abel-transformation in Fig. 6. A near-unity value in Figures 8.a and 8.b suggest regions of high $\mathrm{OH}^{*}$ intensity fluctuation as the standard deviation approaches or, in some cases, exceeds the mean value.

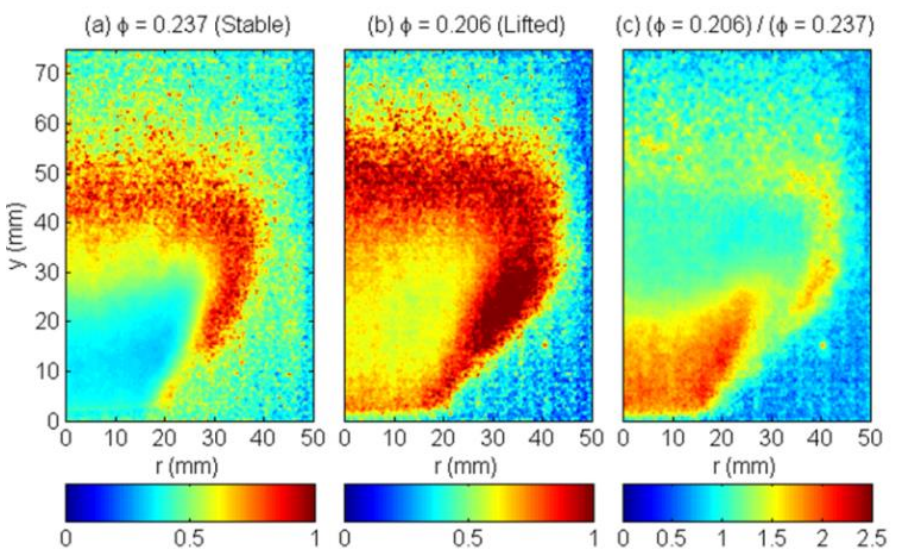

Figure 8. NSD PLOTS OF OH* FOR (a) STABLE AND (b) LIFTED $\mathrm{H}_{2}$-AIR FLAMES, WITH (c) SHOWING (b) NORMALIZED TO (a)

In the stable $\mathrm{H}_{2}$-air flame case of Fig. 8.a, the regions near the burner exit nozzle $(y=0 \mathrm{~mm})$ show relatively low fluctuation, which is in agreement with the Abel-transformed image of Fig. 6.b. The highest fluctuation levels in the stable case occur along the outer shear layer, which is expected given the influence of vortex shedding from the burner nozzle and influence from the outer recirculation zone (further flow field information for this particular swirler in other works [20, 21]), both highly turbulent regions where the LPM $\mathrm{H}_{2}$ flame may exist given its stretched flame response. As the flame moves towards the lifted condition with an increase in air mass flow, the NSD plot of Fig. 8.b is markedly different, showing high $\mathrm{OH}^{*}$ intensity fluctuations in the region near the burner exit and expanding influence from the outer recirculation zone as the flame moves further downstream. To quantify the change in $\mathrm{OH}^{*}$ intensity fluctuation in the lifted condition, the normalized NSD plot in Fig. 8.c. details the regions within the flow field where intensity fluctuations are occurring, notably up to 2.5 times the normalized stable $\mathrm{OH}^{*}$ fluctuation occurs when moving from stable to lifted flame configuration in the region within $20 \mathrm{~mm}$ axially and radially of the burner exit.

This technique is applied further to evaluate the resistance of dilute $\mathrm{H}_{2}$-air flames to lean flame detachment, with results for $35 \mathrm{H}_{2}-65 \mathrm{CO}_{2}$ and $35 \mathrm{H}_{2}-65 \mathrm{H}_{2} \mathrm{O}$ presented in Fig. 9. The NSD plots of Fig. 9.a and 9.b are calculated from the lifted flame conditions plotted as closed symbols in Fig. 5.a and the plots of Fig. 9.c and 9.d are normalized relative to the pure $\mathrm{H}_{2}$-air lifted flame NSD plot in Fig. 8.b.

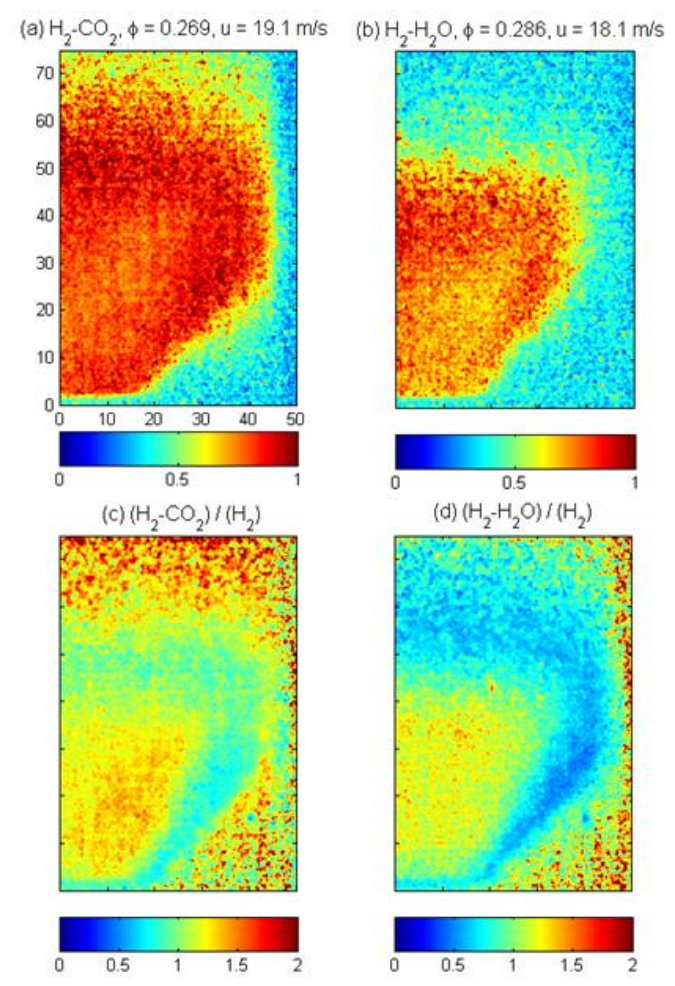

Figure 9. NSD PLOTS OF OH* FOR (a) $35 \mathrm{H}_{2}-65 \mathrm{CO}_{2}$ AND (b)
$35 \mathrm{H}_{2}-65 \mathrm{H}_{2}$ O LIFTED FLAMES, WITH (c) AND (d)
NORMALIZED TO THE $\mathrm{H}_{2}$-AIR PLOT IN FIG. 8.b.

Whereas the stable flame shapes for the corresponding $35 \mathrm{H}_{2}-65 \mathrm{CO}_{2}$ and $35 \mathrm{H}_{2}-65 \mathrm{H}_{2} \mathrm{O}$ flames are nearly identical in Figure 6.c and 6.d, respectively, the flame response under detached conditions is strikingly different. The $35 \mathrm{H}_{2}-65 \mathrm{CO}_{2}$ lifted flame (Fig. 6.a) has an almost uniform high intensity fluctuation spanning the flow field from the burner exit nozzle, along the shear layer, and across the central recirculation zone. Some influence from the outer recirculation zone can also be seen with the start of an M-shaped flame. In the $35 \mathrm{H}_{2}-65 \mathrm{H}_{2} \mathrm{O}$ lifted flame (Fig. 6.b), the intensity fluctuations are also observed to cover the flow field, however this region is more compact than the $\mathrm{H}_{2}-\mathrm{CO}_{2}$ flame while also generally lower in intensity, particularly along the shear layer. Under these conditions, $\kappa_{\text {ext }}$ is expected to be higher for the $35 \mathrm{H}_{2}-65 \mathrm{H}_{2} \mathrm{O}$ flame than the $35 \mathrm{H}_{2}-65 \mathrm{CO}_{2}$ flame, as flame liftoff for the $\mathrm{H}_{2-}$ $\mathrm{H}_{2} \mathrm{O}$ flame occurs at $\varphi=0.286$ compared with $\varphi=0.269$ for the $\mathrm{H}_{2}-\mathrm{CO}_{2}$ flame, which may act to suppress flame fluctuations as the flame approaches detachment and stabilizes within the flow field rather than along the bluff body/exit nozzle. While it may dampen the fluctuations, increased $\kappa_{e x t}$ cannot keep the $\mathrm{H}_{2}-$ $\mathrm{H}_{2} \mathrm{O}$ flame attached to the burner exit nozzle, as turbulence levels are nearly $15 \%$ lower in the $\mathrm{H}_{2}-\mathrm{H}_{2} \mathrm{O}$ lifted case (due mainly to differences in dynamic viscosity between $\mathrm{H}_{2} \mathrm{O}$ and $\mathrm{CO}_{2}$ ), thereby reducing $\mathrm{H}_{2}$ turbulent flame speed. Normalization by the pure $\mathrm{H}_{2}$-air lifted NSD plot (Fig. 8.b) indicates that both $\mathrm{H}_{2}-\mathrm{CO}_{2}$ and $\mathrm{H}_{2}-\mathrm{H}_{2} \mathrm{O}$ flames are subject to more fluctuation under lifted conditions, with the $\mathrm{H}_{2}-\mathrm{CO}_{2}$ lifted case showing highest fluctuations in the central core, which could be expected given the high $R e$ and expected low $\kappa_{e x t}$ relative to the other flames. 


\subsubsection{EXHAUST GAS EMISSIONS}

Given the low AFT of the ultra-lean conditions investigated, the thermal $\mathrm{NO}_{\mathrm{x}}$ formation pathway is effectively reduced, in addition to the reduction of premixed $\mathrm{N}_{2}$ concentration with $\mathrm{CO}_{2}$ or $\mathrm{H}_{2} \mathrm{O}$ addition. The lack of hydrocarbons also eliminates the prompt $\mathrm{NO}_{\mathrm{x}}$ pathway, as highlighted by Glarborg et al. [32]. Given the suppression of thermal and prompt $\mathrm{NO}_{\mathrm{x}}$ pathways under these conditions, it is expected that the $\mathrm{N}_{2} \mathrm{O}$ and $\mathrm{NNH}$ pathways contribute, particularly with increasing pressure [32]. Measured $\mathrm{NO}_{\mathrm{x}}$ emissions could be achieved at the $125 \mathrm{~kW} / \mathrm{MPa}$ scaling, with total $\mathrm{NO}_{\mathrm{x}}$ (combined $\mathrm{NO}$ and $\left.\mathrm{NO}_{2}\right)<1 \mathrm{ppm}$ in $\mathrm{H}_{2}-\mathrm{CO}_{2}$ cases and $<2$ ppm across all other experimental conditions. However, high $\mathrm{CO}$ emissions were measured at low AFT in the $\mathrm{H}_{2}-\mathrm{CO}_{2}$ cases with high $\mathrm{CO}_{2}$ dilution as shown in Fig. 10 . While a similar trend could be expected for $\mathrm{LPM} \mathrm{CH}_{4}$-air flames with reduction in AFT [33], the mechanism for $\mathrm{CO}$ formation differs from incomplete hydrocarbon oxidation and is instead attributed to the $\mathrm{CO}_{2}+\mathrm{H}=\mathrm{CO}+\mathrm{OH}$ reaction, similar to that suggested by Glarborg and Bentzen [34] for high $\mathrm{CO}_{2-}$ dilution of $\mathrm{CH}_{4}$-oxyfuel combustion.

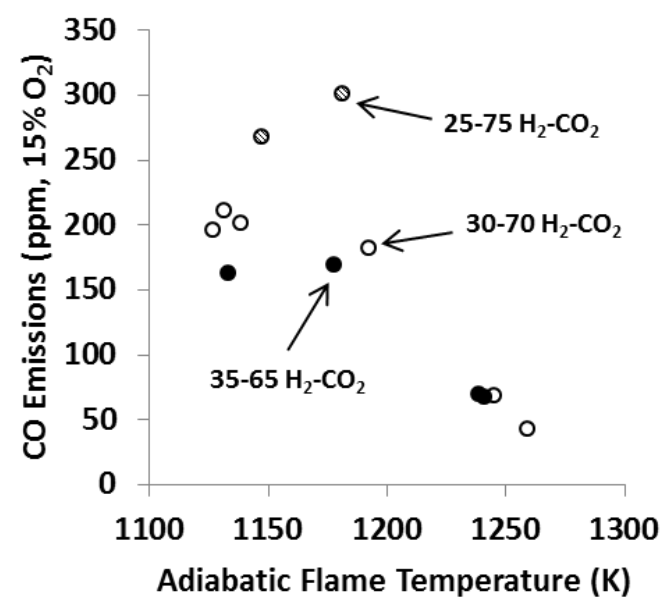

Figure 10. CO EMISSIONS FROM $\mathrm{H}_{2}-\mathrm{CO}_{2} 12.5 \mathrm{~kW}$ FLAMES

\subsubsection{ELEVATED PRESSURE (125 kW/MPa Scaling)}

As the burner pressure is increased, the associated increase in premixed reactant density is offset by an increase in mass flow to maintain a similar bulk flow profile. By holding $\varphi$ constant at 0.25 , it is therefore possible to evaluate flame stability as a function of the dilution rate. Abel-transformed images of stable $55 \mathrm{H}_{2}-45 \mathrm{CO}_{2}$ and $55 \mathrm{H}_{2}-45 \mathrm{H}_{2} \mathrm{O}$ flames at $P 2=$ $0.15 \mathrm{MPa}$ are shown in Figures 11.a and 11.c, respectively, along with lifted flame NSD plots for increasing diluent content at the same $P 2$. For the stable flame conditions, a comparison can be made between Figures 11.a and 6.c $\left(\mathrm{H}_{2}-\mathrm{CO}_{2}\right)$ as well as Figures 11.b and 6.d $\left(\mathrm{H}_{2}-\mathrm{H}_{2} \mathrm{O}\right)$, noting the similar flame stabilization location along the outward expanding shear layer. Similar reactivity between these two different operating conditions, 1) $35 \% \mathrm{H}_{2}$ at $\varphi=0.3$ in Fig. 6 and 2) $55 \% \mathrm{H}_{2}$ at $\varphi=$ 0.25 in Fig. 11, might be expected given the nominally equal AFT and $\bar{u}$ for each diluent $\left(S_{L}\right.$ and $\kappa_{e x t}$ could not be modelled at these conditions). In the $\mathrm{H}_{2}-\mathrm{CO}_{2}$ case, the AFT in Fig. 6.c is $1178 \mathrm{~K}$ compared to $1180 \mathrm{~K}$ in Fig. 11.a. In the $\mathrm{H}_{2}-\mathrm{H}_{2} \mathrm{O}$ case, the AFT in Fig. 6.d is $1215 \mathrm{~K}$ compared to $1197 \mathrm{~K}$ in Fig. 11.a. The value of $\bar{u}$ increases by $\sim 4 \%$ to $18.4 \mathrm{~m} / \mathrm{s}$ between these conditions.
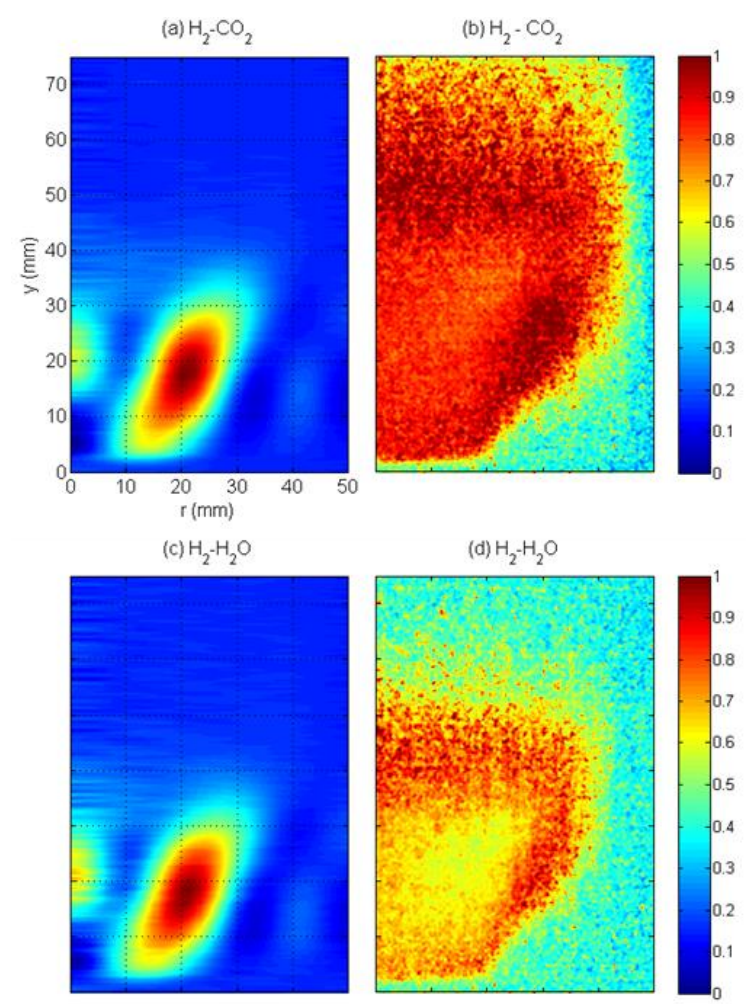

Figure 11. ABEL-TRANSFORMED OH* FOR STABLE (a) $55 \mathrm{H}_{2}-45 \mathrm{CO}_{2}$ and (c) $55 \mathrm{H}_{2}-45 \mathrm{H}_{2} \mathrm{O}$ FLAMES AT $\varphi=0.25, P 2=$ $0.15 \mathrm{MPa}$. ASSOCIATED NSD PLOTS (b, d) FOR LIFTED FLAMES WITH INCREASED DILUTION.

Despite the similar AFT and $\bar{u}$, the flame brush is observed to be more compact at $P 2=0.15 \mathrm{MPa}$ than at atmospheric conditions in Fig. 6. For example, the $50 \% \mathrm{OH}^{*}$ intensity contour (blue-green), extends beyond $y=40 \mathrm{~mm}$ in Fig. 6 for both diluents, however in Fig. 11, this contour extends just beyond $y=30 \mathrm{~mm}$. This is attributed to two key factors. First, the relatively low $\bar{u}$ is not sufficient to balance the increasing flame propagation speed as turbulence increases with pressure using this flow scaling method (due to the reduction in premixed reactant dynamic viscosity, thus increasing $R e$ ). Second, as highlighted by the chemical kinetic modelling, it is expected that $\kappa_{e x t}$ would increase with a relatively small change in pressure for these dilution rates. Thus, the thermodiffusive effects allow for flame stabilization in this region of increased turbulence. This is further supported by considering the NSD plots in Figures 11.b and 11.d for $\mathrm{H}_{2-}$ $\mathrm{CO}_{2}$ and $\mathrm{H}_{2}-\mathrm{H}_{2} \mathrm{O}$, respectively.

In both cases, the maximum dilution to achieve flame detachment increased over the equivalent $\varphi=0.25$ condition at atmospheric pressure, with increased turbulence and thermodiffusive effects balancing the reaction limiting physical and chemical effects of dilution. Maximum $\mathrm{CO}_{2}$ fuel dilution increased from $56.7 \%$ to $57.5 \%$ and maximum $\mathrm{H}_{2} \mathrm{O}$ fuel dilution increased from $55.1 \%$ to $55.7 \%$. As predicted by the chemical kinetic modelling, the rate of increase of $\kappa_{e x t}$ with increasing pressure for $\mathrm{H}_{2}-\mathrm{H}_{2} \mathrm{O}$ blends is expected to be higher than the $\mathrm{H}_{2}-\mathrm{CO}_{2}$ blends, and the NSD plots support this as $\mathrm{OH}^{*}$ intensity fluctuations near flame detachment are reduced in the regions of highest expected turbulence (e.g. axial shear layer) compared with the $\mathrm{H}_{2}-\mathrm{CO}_{2}$ which exhibits high intensity fluctuations along the shear layer and at the burner exit nozzle. 
At this thermal power scaling, the burner was not operated above $0.15 \mathrm{MPa}$ due to sudden flame flashback, even at high dilution rates ( $>60 \%$ Fuel Diluent), which was unexpected as the burner was operated without diluent at nearly $\varphi=0.25$ at $P 2=0.11 \mathrm{MPa}$. This is similarly attributed to the increased turbulence effect with increasing pressure which promotes flame propagation upstream in this low $\bar{u}$ condition.

\subsubsection{ELEVATED PRESSURE (250 kW/MPa Scaling)}

To extend the pressurized operation of the HPGSB-2 beyond $0.15 \mathrm{MPa}$, the thermal power scaling of $125 \mathrm{~kW} / \mathrm{MPa}$ was increased to $250 \mathrm{~kW} / \mathrm{MPa}$ and the burner inlet temperature was increased from $523 \mathrm{~K}$ to $573 \mathrm{~K}$, in an effort to increase bulk velocity through the burner and reduce heat loss the rig. Thus, exhaust temperatures $>1000 \mathrm{~K}$ could be achieved under these conditions. Similar to the operation at $125 \mathrm{~kW} / \mathrm{MPa}$, the burner pressure was increased at a fixed $\varphi=0.25$, with total mass flow rate scaling in proportion. At each pressure condition, the maximum diluent addition to achieve an intermittent detached flame was identified, with the results for $\mathrm{CO}_{2}$ dilution presented in Fig. 12. Note that required steam flows could not be achieved at these conditions. In Fig. 12, mean exit nozzle velocity is within the range $46.7<\bar{u}<48.2$ $\mathrm{m} / \mathrm{s}$, with a maximum air flow of $71.5 \mathrm{~g} / \mathrm{s}$ and $\mathrm{CO}_{2}$ flow of $11.65 \mathrm{~g} / \mathrm{s}$ at $0.275 \mathrm{MPa}$.

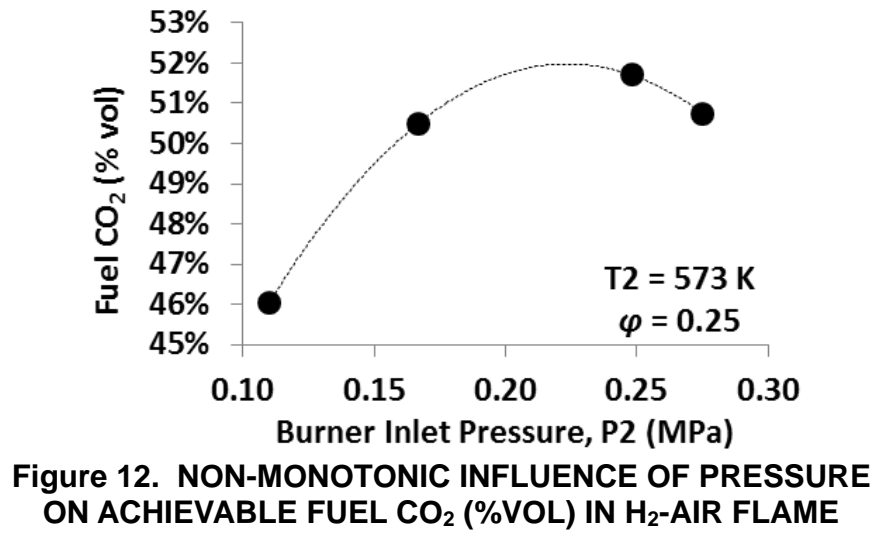

As shown in Fig. 12, the maximum \%vol $\mathrm{CO}_{2}$ diluent increases from $0.11 \mathrm{MPa}$ to $0.15 \mathrm{MPa}$, in agreement with the observation made in the $125 \mathrm{~kW} /$ bar case, although notably at lower total \%vol $\mathrm{CO}_{2}$ dilution ratios in this case. The maximum \%vol $\mathrm{CO}_{2}$ diluent increases until approximately $0.225 \mathrm{MPa}$ (best fit), after which it then decreases for the 0.25 $\mathrm{MPa}$ and $0.275 \mathrm{MPa}$ conditions. This nonmonotonic pressure dependence behavior is in agreement with the nonmonotonic behavior of dilute $\mathrm{H}_{2}$-air $\kappa_{\text {ext }}$ with increasing pressure predicted by the chemical kinetic modelling in Fig. 4. This would also be in agreement with the nonmonotonic $\kappa_{\text {ext }}$ trend identified by Niemann et al. [18] for $\mathrm{H}_{2}-\mathrm{N}_{2}$-air pressurized diffusion counterflow flames. Despite the fact that the Li et al. [27] mechanism is unable to converge at these ultra-lean, dilute conditions, the trends identified at higher $\varphi$ give an indication that the lean stability of dilute $\mathrm{H}_{2}$-air flames, measured here under turbulent pressurized conditions, is increasingly influenced by thermodiffusive effects which may present important operational considerations for $\mathrm{H}_{2}$-based GTs. Furthermore, it appears viable for the use of $\kappa_{\text {ext }}$ to predict pressurized lean $\mathrm{H}_{2}$ flame stability and requires further detailed investigation.

\section{CONCLUSIONS}

This study presents experimental measurements supported by chemical kinetics modelling at elevated temperature for both atmospheric $(12.5 \mathrm{~kW})$ and elevated pressure $(125 \mathrm{~kW} / \mathrm{MPa}$ and $250 \mathrm{~kW} / \mathrm{MPa}) \mathrm{H}_{2}$-air, $\mathrm{H}_{2}-\mathrm{CO}_{2}$-air and $\mathrm{H}_{2}-\mathrm{H}_{2} \mathrm{O}$-air LPM flames. Time-resolved $\mathrm{OH}^{*}$ chemiluminescence characterizes the influence of fuel dilution on resulting flame stabilization from a lean detached flame limit to a rich flashback limit. Exhaust gas emissions from these ultra-lean flames were measured to prove low- $\mathrm{NO}_{\mathrm{x}}$ operation is possible, however this at the expense of reduced combustor exhaust temperatures and increased $\mathrm{CO}$ emissions in the $\mathrm{H}_{2}-\mathrm{CO}_{2}$-air case. This suggests that alternative architectures or operating condition may be necessary in future work to provide practical thermal output from the burner, such as staged diffuse $\mathrm{H}_{2}$ injection. This study provides a detailed analysis for the use of pure and dilute $\mathrm{H}_{2}$-air in a representative GT burner geometry designed for $\mathrm{CH}_{4}$ without any additional retrofit. The following conclusions are made:

1. Successful stabilization of pure $\mathrm{H}_{2}$-air flames in a $\mathrm{CH}_{4}$-air swirl burner requires operation at low equivalence ratio $(\varphi<$ 0.25 ) with sufficiently high burner exit nozzle velocity. The stable operating equivalence ratio could be increased with sufficient levels of $\mathrm{CO}_{2}$ dilution (up to $75 \% \mathrm{vol}$ fuel or $40 \% \mathrm{vol}$ premix) or $\mathrm{H}_{2} \mathrm{O}$ dilution (up to $70 \%$ vol fuel or $23 \%$ vol premix) and turbulence $\left(\mathrm{Re}_{\mathrm{H} 2} \approx 2 * \mathrm{Re}_{\mathrm{CH} 4}\right)$. However, this comes with an associated $\Delta P$ penalty.

2. Chemical kinetics modelling of $S_{L}$, AFT, and $\kappa_{\text {ext }}$ enabled identification of stable ignition points for $\mathrm{H}_{2}$-based fuels (near $65 \%$ fuel diluent). A reduction in $\varphi$ and varying amounts of fuel dilution with $\mathrm{CO}_{2}$ or $\mathrm{H}_{2} \mathrm{O}$ is required to reduce the pure $\mathrm{H}_{2-}$ air values within range of stable $\mathrm{CH}_{4}$-air flames, with $\mathrm{CO}_{2}$ influencing the reduction rate more than $\mathrm{H}_{2} \mathrm{O}$.

3. Pure and dilute $\mathrm{H}_{2}$-air flames under atmospheric pressure, preheated conditions are characterized by low $\mathrm{OH}^{*}$ intensity, with $\mathrm{H}_{2}-\mathrm{H}_{2} \mathrm{O}$ flames significantly lower than pure $\mathrm{H}_{2}$-air and $\mathrm{H}_{2}-\mathrm{CO}_{2}$ flames. NSD plots of $\mathrm{OH}^{*}$ intensity fluctuation under lifted flame conditions show that $\mathrm{H}_{2}-\mathrm{H}_{2} \mathrm{O}$ flames are more stable than $\mathrm{H}_{2}-\mathrm{CO}_{2}$, attributed to increased $\kappa_{\text {ext }}$.

4. Ultra-low $\mathrm{NO}_{\mathrm{x}}$ emissions could be achieved: $<1 \mathrm{ppm}$ in $\mathrm{H}_{2^{-}}$ $\mathrm{CO}_{2}$ cases and $<2$ ppm across all other experimental conditions. This is attributed to the ultra-lean operation, which limits thermal $\mathrm{NO}_{\mathrm{x}}$ formation. $\mathrm{N}_{2} \mathrm{O}$ and $\mathrm{NNH}$ pathways may therefore be contributing. High $\mathrm{CO}$ emissions at low AFT in the $\mathrm{H}_{2}-\mathrm{CO}_{2}$ cases were measured, attributed to the $\mathrm{CO}_{2}+\mathrm{H}=$ $\mathrm{CO}+\mathrm{OH}$ reaction.

5. At low $\bar{u}$ corresponding to $125 \mathrm{~kW} / \mathrm{MPa}$ scaling, burner operation above $0.15 \mathrm{MPa}$ could not be achieved without flashback. By increasing the total mass flow through the burner at $250 \mathrm{~kW} / \mathrm{MPa}$, pressurized dilute $\mathrm{H}_{2}$-air flames up to 0.275 MPa could be realized due to increased $\bar{u}$.

6. Maximum levels of $\mathrm{CO}_{2}$ dilution in pressurized $\mathrm{H}_{2}$-air flames exhibit a nonmonotonic influence with increasing $P 2$, suggesting that thermodiffusive effects dominate under these highly stretched, lean conditions, in agreement with the similar nonmonotonic $\kappa_{\text {ext }}$ trend with pressure identified by chemical kinetics modelling. 


\section{ACKNOWLEDGMENTS}

This work was supported by funding from the FLEXIS project (Welsh European Funding Office) and the UK EPSRC Advanced Gas Turbine project (EP/M015300/1). Mr. Jack Thomas is thankfully acknowledged for his work operating and maintaining the experimental facility described herein.

\section{REFERENCES}

[1] Wezel, Ralf and Clarena Barón, Sònia. "The Turbine Industry Commits to Provide Europe with "Renewable Gas-Ready" Turbines." Mechanical Engineering Vol. 141 No. 9 (2019): pp. 56-57.

[2] International Energy Agency (IEA). "The Future of Hydrogen." IEA Publications, Paris (2019). Available online: https://webstore.iea.org/the-future-of-hydrogen. [Accessed November $\left.18^{\text {th }}, 2019\right]$

[3] Stathopoulos, P., Kuhn, P., Wendler, J., Tanneberger, T., Terhaar, S., Paschereit, C.O., Schmalhofer, C., Griebel, P., Aigner, M. "Emissions of a Wet Premixed Flame of Natural Gas and a Mixture with Hydrogen at High Pressure." Journal of Engineering for Gas Turbines and Power Vol. 139 No. 4 (2017): pp. 041507. DOI 10.1115/1.4034687 https://asmedigitalcollection.asme.org/gasturbinespower/articleabstract/139/4/041507/444277/Emissions-of-a-Wet-Premixed-Flameof-Natural-Gas

[4] Mayer, C., Sangl, J., Sattlemayer, T., Lachaux T., Bernero, S. "Study on the Operational Window of a Swirl Stabilized Syngas Burner Under Atmospheric and High Pressure Conditions." Journal of Engineering for Gas Turbines and Power Vol. 134 No. 3 (2012): pp. 031506. DOI 10.1115/1.4004255

https://asmedigitalcollection.asme.org/gasturbinespower/articleabstract/134/3/031506/455909/Study-on-the-Operational-Window-ofa-Swirl

[5] Sanchez, Antonio L. and Williams, Forman A. "Recent advances in understanding of flammability characteristics of hydrogen." Progress in Energy and Combustion Science Vol. 41 (2014): pp. 1-55. DOI 10.1016/j.pecs.2013.10.002.

https://www.sciencedirect.com/science/article/pii/S0360128513000518

[6] Reichel, Thoralf G., Terhaar, Steffen, Paschereit, Oliver. "Increasing Flashback Resistance in Lean Premixed Swirl-Stabilized Hydrogen Combustion by Axial Air Injection." Journal of Engineering for Gas Turbines and Power Vol. 137 No. 7 (2015): pp. 071503. DOI 10.1115/1.4029119.

https://asmedigitalcollection.asme.org/gasturbinespower/articleabstract/137/7/071503/373737/

[7] Strakey, P.A., Woodruff, S.D., Williams, T.C., and Schefer, R.W. "OH-Planar Fluorescence Measurements of Pressurized, Hydrogen Premixed Flames in the SimVal Combustor." AIAA Journal Vol. 46 No. 7 (2008): pp. 1604-1613. DOI 10.2514/1.32640. https://arc.aiaa.org/doi/10.2514/1.32640

[8] Strakey, P., Sidwell, T., and Ontko, J. "Investigation of the effects of hydrogen addition on lean extinction in a swirl stabilized combustor." Proceedings of the Combustion Institute Vol. 31 (2007): pp.3173-3180. DOI 10.1016/j.proci.2006.07.077.

https://www.sciencedirect.com/science/article/pii/S1540748906000940
[9] Boerner, S., Funke, H.H.-W., Hendrick, P., Recker, E., and Elsing, R. "Development and Integration of a Scalable Low $\mathrm{NO}_{\mathrm{x}}$ Combustion Chamber for a Hydrogen-Fueled Aerogas Turbine." Progress in Propulsion Physics Vol. 4 (2013): pp. 357-372

DOI 10.1051/eucass/201304357.

https://www.eucass-

proceedings.eu/articles/eucass/abs/2013/01/eucass4p357/eucass4p357. $\underline{\mathrm{html}}$

[10] Bower, Hannah E., Schwärzle, Andreas, Grimm, Felix, Zornek, Timo, and Kutne, Peter. "Experimental Analysis of a Micro Gas Turbine Combustor Optimized for Flexible Operation with Various Gaseous Fuel Compositions." Journal of Engineering for Gas Turbines and Power Vol. 142 No. 3 (2020): pp. 031015. DOI 10.1115/1.4044901.

https://asmedigitalcollection.asme.org/gasturbinespower/articleabstract/142/3/031015/975754/Experimental-Analysis-of-a-MicroGas-Turbine

[11] Bothien, Mirko R., Ciani, Andrea, Wood, John P., and Fruechtel, Gerhard. "Toward Decarbonized Power Generation with Gas Turbines by Using Sequential Combustion for Burning Hydrogen." Journal of Engineering for Gas Turbines and Power Vol. 141 No. 12 (2019): pp. $121013 . \quad$ DOI $10.1115 / 1.4045256$. https://asmedigitalcollection.asme.org/gasturbinespower/articleabstract/141/12/121013/1065885/

[12] Weiland, Nathan T. and Strakey, Peter A. " $\mathrm{NO}_{\mathrm{x}}$ Reduction by AirSide versus Fuel-Side Dilution in Hydrogen Diffusion Flame Combustors." Journal of Engineering for Gas Turbines and Power Vol. 132 No. 7 (2010): pp. 071504. DOI 10.1115/1.4000268. https://asmedigitalcollection.asme.org/gasturbinespower/articleabstract/132/7/071504/408835/

[13] Tanneberger, Tom, Schimek, Sebastian, Paschereit, Christian Oliver, and Stathopoulos, Panagiotis. "Efficiency Measurement Approach for a Hydrogen Oxyfuel Combustor." Journal of Engineering for Gas Turbines and Power Vol. 141 No. 10 (2019): pp. 101023. DOI 10.1115/1.4044779.

https://asmedigitalcollection.asme.org/gasturbinespower/articleabstract/141/10/101023/975424/

[14] Masri, A.R., Dibble, R.W., and Barlow, R.S. "Chemical kinetic effects in nonpremixed flames of $\mathrm{H}_{2} / \mathrm{CO}_{2}$ fuel." Combustion and Flame Vol. 91 No. 3-4 (1992): pp. 285-309. DOI 10.1016/00102180(92)90059-X.

https://www.sciencedirect.com/science/article/abs/pii/0010218092900 $\underline{59 X}$

[15] Cong, Tanh Le and Dagaut, Philippe. "Oxidation of $\mathrm{H}_{2} / \mathrm{CO}_{2}$ mixtures and effect of hydrogen initial concentration on the combustion of $\mathrm{CH}_{4}$ and $\mathrm{CH}_{4} / \mathrm{CO}_{2}$ mixtures: Experiments and modelling." Proceedings of the Combustion Institute Vol. 32 No. 1 (2009): pp. 427-435. DOI 10.1016/j.proci.2008.05.079. https://www.sciencedirect.com/science/article/pii/S1540748908003490

[16] Kuznetsov, M., Redlinger, R., Breitung, W., Grune, J., Friedrich, A., and Ichikawa, N. "Laminar burning velocities of hydrogenoxygen-steam mixtures at elevated temperatures and pressure." Proceedings of the Combustion Institute Vol. 33 No. 1 (2011): pp. 895-903. DOI 10.1016/j.proci.2010.06.050.

https://www.sciencedirect.com/science/article/pii/S1540748910000763 
[17] Lyu, Yajin, Qiu, Penghua, Liu, Li, Yang, Chenchen, and Sun, Shaozeng. "Effects of steam dilution on laminar flame speeds of $\mathrm{H}_{2} /$ air $/ \mathrm{H}_{2} \mathrm{O}$ mixtures at atmospheric and elevated pressures." International Journal of Hydrogen Energy Vol. 43 No. 15 (2018): pp. 7538-7549. DOI 10.1016/j.ijhydene.2018.02.065.

https://www.sciencedirect.com/science/article/pii/S0360319918304828

[18] Niemann, U., Seshadri, K., and Williams, F.A. "Effect of pressure on structure and extinction of near-limit hydrogen counterflow diffusion flames." Proceedings of the Combustion Institute Vol. 34 No. 1 (2013): pp. 881-886. DOI 10.1016/j.proci.2012.06.145.

https://www.sciencedirect.com/science/article/pii/S1540748912002532

[19] Göke, Sebastian, Füri, Marc, Bourque, Gilles, Bobusch, Bernhard, Göckeler, Katharina, Krüger, Oliver, Schimek, Sebastian, Terhaar, Steffen, and Paschereit, Christian Oliver. "Influence of steam dilution on the combustion of natural gas and hydrogen in premixed and richquench-lean combustors." Fuel Processing Technology Vol. 107 (2013): pp. 14-22. DOI 10.1016/j.fuproc.2012.06.019.

https://www.sciencedirect.com/science/article/pii/S0378382012002408

[20] Runyon, Jon, Marsh, Richard, Bowen, Philip, Pugh, Daniel, Giles, Anthony, and Morris, Steve. "Lean methane flame stability in a premixed generic swirl burner: Isothermal flow and atmospheric combustion characterization." Experimental Thermal and Fluid Science Vol. 92 (2018): pp. 125-140. DOI 10.1016/j.expthermflusci.2017.11.019.

https://www.sciencedirect.com/science/article/pii/S0894177717303722

[21] Runyon, Jon P., Giles, Anthony, Marsh, Richard, Pugh, Daniel, Goktepe, Burak, Bowen, Philip, and Morris, Steven. "Characterization of Additive Layer Manufacturing Swirl Burner Surface Roughness and Its Effects on Flame Stability Using High-Speed Diagnostics." Journal of Engineering for Gas Turbines and Power Vol. 142 No. 4 (2020): $\quad$ pp. $041017 . \quad$ DOI 10.1115/1.4044950. https://asmedigitalcollection.asme.org/gasturbinespower/article/142/4/ 041017/1031151/Characterization-of-Additive-Layer-Manufacturing

[22] Pugh, Daniel, Bowen, Philip, Valera-Medina, Agustin, Giles, Anthony, Runyon, Jon, and Marsh, Richard. "Influence of steam addition and elevated ambient conditions on $\mathrm{NO}_{\mathrm{x}}$ reduction in a staged premixed swirling $\mathrm{NH}_{3} / \mathrm{H}_{2}$ flame." Proceedings of the Combustion Institute Vol. 37 No. 4 (2019): pp. 5401-5409. DOI 10.1016/j.proci.2018.07.091.

https://www.sciencedirect.com/science/article/pii/S1540748918305091

[23] Runyon, Jon, Marsh, Richard, Pugh, Daniel, Bowen, Philip, Giles, Anthony, Morris, Steven, and Valera-Medina, Agustin. "Experimental Analysis of Confinement and Swirl Effects on Premixed $\mathrm{CH}_{4}-\mathrm{H}_{2}$ Flame Behavior in a Pressurized Generic Swirl Burner." Proceedings of the ASME Turbo Expo 2017: Turbomachinery Technical Conference and Exposition. GT2017-64794: pp. V04BT04A044. Charlotte, NC, June 26-30, 2017. DOI 10.1115/GT2017-64794. http://proceedings.asmedigitalcollection.asme.org/proceeding.aspx?arti cleid $=2650020$.

[24] Gaydon, A. G. The Spectroscopy of Flames, 2nd Edition. Chapman and Hall, London (1974).

[25] ANSYS Chemkin-Pro 2019 R2, ANSYS, Inc, Canonsburg, Pennsylvania (2019).

[26] Smith, Gregory P., Golden, David M., Frenklach, Michael, Moriarty, Nigel W., Eiteneer, Boris, Goldenberg, Mikhail, Bowman, C. Thomas, Hanson, Ronald K., Song, Soonho, Gardiner Jr., William C., Lissianski, Vitali V., and Qin, Zhiwei. "The 'GRIMech 3.0' chemical kinetic mechanism.” (1999) www.me.berkeley.edu/grimech.
[27] Li, Juan, Zhao Zhenwei, Kazakov, Andrei, Chaos, Marcos, Dryer, Frederick L., and Scire Jr., James J. "A comprehensive kinetic mechanism for $\mathrm{CO}, \mathrm{CH}_{2} \mathrm{O}$, and $\mathrm{CH}_{3} \mathrm{OH}$ combustion." International Journal of Chemical Kinetics Vol. 39 No. 3 (2007): pp. 109-136. DOI 10.1002/kin.20218

https://onlinelibrary.wiley.com/doi/10.1002/kin.20218

[28] Shanbhogue, S.J., Sanusi, Y.S., Taamallah, S., Habib, M.A., Mokheimer, E.M.A, and Ghoniem, A.F. "Flame macrostructures, combustion instability and extinction strain scaling in swirl-stabilized premixed $\mathrm{CH}_{4} / \mathrm{H}_{2}$ combustion." Combustion and Flame Vol. 163 (2016): pp. 494-507. DOI 10.1016/j.combustflame.2015.10.026. https://www.sciencedirect.com/science/article/pii/S001021801500382 $\underline{X}$

[29] Hu, Erjiang, Huang, Zuohua, He, Jiajia, Jin, Chun, and Zheng, Jianjun. "Experimental and numerical study on laminar burning characteristics of premixed methane-hydrogen-air flames." International Journal of Hydrogen Energy Vol. 34 No. 11 (2009): pp. 4876-4888. DOI 10.1016/j.ijhydene.2009.03.058

https://www.sciencedirect.com/science/article/pii/S0360319909004868

[30] Shaddix, C. and Molina, A. "Ignition, flame stability, and char combustion in oxy-fuel combustion." Oxy-Fuel Combustion for Power Generation and Carbon Dioxide $\left(\mathrm{CO}_{2}\right)$ Capture. Woodhead Publishing, Cambridge (2011): pp. 101-124

[31] Amato, Alberto, Seitzman, Jerry M., Lieuwen, Timothy C., C. and Molina, A. "Emissions from Oxyfueled or High-Exhaust Gas Recirculation Turbines." Gas Turbine Emissions. Cambridge University Press, New York (2013): pp. 209-234.

[32] Glarborg, Peter, Miller, James A., Ruscic, Branko, Klippenstein, Stephen J. "Modeling nitrogen chemistry in combustion." Progress in Energy and Combustion Science Vol. 67 (2018): pp. 31-68.

DOI 10.1016/j.pecs.2018.01.002

https://www.sciencedirect.com/science/article/pii/S0360128517301600

[33] Pavri, R., Moore, G. D. "Gas Turbine Emissions and Control." General Electric Power Systems (2001). Report No. GER 4211.

[34] Glarborg, Peter and Bentzen, Line L. B. "Chemical Effects of a High $\mathrm{CO}_{2}$ Concentration in Oxy-Fuel Combustion of Methane." Energy and Fuels Vol. 22 No. 1 (2008): pp. 291-296.

DOI 10.1021/ef7005854. https://pubs.acs.org/doi/10.1021/ef7005854 